\title{
Review Article \\ Pros and Cons of Antigen-Presenting Cell Targeted Tumor Vaccines
}

\author{
Cleo Goyvaerts and Karine Breckpot
}

Laboratory of Molecular and Cellular Therapy, Department of Biomedical Sciences, Vrije Universiteit Brussel, 1090 Brussels, Belgium

Correspondence should be addressed to Karine Breckpot; kbreckpo@vub.ac.be

Received 28 February 2015; Revised 26 August 2015; Accepted 3 September 2015

Academic Editor: David E. Gilham

Copyright (C) 2015 C. Goyvaerts and K. Breckpot. This is an open access article distributed under the Creative Commons Attribution License, which permits unrestricted use, distribution, and reproduction in any medium, provided the original work is properly cited.

In therapeutic antitumor vaccination, dendritic cells play the leading role since they decide if, how, when, and where a potent antitumor immune response will take place. Since the disentanglement of the complexity and merit of different antigen-presenting cell subtypes, antitumor immunotherapeutic research started to investigate the potential benefit of targeting these subtypes in situ. This review will discuss which antigen-presenting cell subtypes are at play and how they have been targeted and finally question the true meaning of targeting antitumor-based vaccines.

\section{Introduction}

Active immunotherapy aims to administer the appropriate tumor associated antigens (TAAs) in such a way that antigenpresenting cells (APCs) can process and present them to oncolytic effector cells in order to eradicate primary and metastasized cancer cells. Since the dendritic cell (DC) is the most professional APC, ex vivo loaded and stimulated DCs were initially used to achieve this response. However, the ex vivo generation and modification of DCs turned out to be a labor-intensive, time- and money-consuming procedure. Furthermore, the variability in DC sources, techniques, and vectors used for TAA transfer led to much diversity in reported TAA expression [1]. Moreover, the in vitro generated DCs may not represent the most suited DC subtype for the induction of a $\mathrm{CD} 4^{+} \mathrm{T}$ helper $1\left(\mathrm{~T}_{\mathrm{H}} 1\right)$ polarized antitumor immune response. To reduce the $\mathrm{DC}$ generation linked variability and exploit the functional characteristics of relevant DC subtypes, naturally circulating DCs have been tested for the induction of long-lasting clinical benefits [2]. Nevertheless, as the isolation of patient-specific DCs remains a labor-intensive and expensive task, direct targeting of TAAs to DCs in situ represents a straightforward and therefore preferred strategy. Moreover, direct delivery of cargo to DCs in situ could offer additional benefits such as (1) generation of scalable, stable, and standardized vaccines,
(2) the ability to tune the direction and strength of the immune response (humoral versus cell-mediated), and (3) improvement of the vaccine's safety profile by reducing the required dose that ends up in nontarget cells and as such diminishing the risk on adverse events. Therefore, numerous groups have evaluated APC targeted vaccination approaches [3-8]. To remain within the scope of this review, we will limit this discussion to APC targeted strategies evaluated in the framework of antitumor immunotherapy.

\section{Which Cells Should Be Targeted?}

2.1. Dendritic Cells as the Most Professional Antigen-Presenting Cells. The art of antigen processing and presentation to naive T cells via major histocompatibility complex (MHC) classes I and II molecules is a privileged feature of three hematopoietic cell types: DCs, macrophages, and B lymphocytes. While the latter two also conduct other functions in innate and humoral immunity, respectively, the former are the most professional and fulltime APCs and are up to 1000-fold more efficient in activating resting $\mathrm{T}$ cells [9]. The fact that DCs are specialized APCs is reflected in numerous phenotypic and functional features.

2.1.1. Phenotypically. DCs are characterized by stellate cytoplasmic protrusions, which endow them with an elongated 
contact surface for antigen capture and presentation [10]. Their specialized antigen capturing features are further evidenced by the notion of several antigen uptake receptors such as DC inhibitory receptor 2 (DCIR2) and DEC205 [11] next to their unique capability to cross-present exogenous antigens to $\mathrm{CD}^{+} \mathrm{T}$ cells upon uptake of draining antigens and antigen handover from migratory DCs [12] or by acquiring peptideMHC complexes also known as "cross-dressing" [13]. As opposed to macrophages, they are further able to regulate their processing capacity and by degrading their engulfed cargo more slowly, they can control lysosomal degradation in order to preserve peptides for T-cell recognition [14]. Next to the presence of MHC/peptide complexes, DCs also express several costimulatory molecules in order to properly guide the naive T cells [15].

2.1.2. Functionally. Next to these structural features, DCs have a remarkable functional plasticity. To accomplish this, they are strategically positioned at body barriers and organ entry ports [16]. On the one hand, they are able to induce immune responses against invading pathogens (nonself). On the other hand, DCs can induce tolerance in order to avoid unwanted immune reactions against autoantigens (self) [17]. In general, immature DCs efficiently take up pathogens, apoptotic cells, and particulate antigens from the environment by receptor-mediated phagocytosis, macropinocytosis, or caveolae and clathrin-mediated endocytosis. Furthermore, they remain tissue-resident, have a high turnover rate of MHC-II/peptide complexes, and lack T-cell stimulatory molecules and hence induce T-cell energy instead of $\mathrm{T}$ cell activation upon DC-T cell interaction [18]. In contrast, activated DCs are considered to be immunogenic. Upon maturation, they lose their endo- and phagocytic receptors and slow down their antigen capture and processing rate, while they upregulate both "signal two" molecules like costimulatory molecules (e.g., CD80 and CD86) and "signal three" molecules (e.g., IL-12) to stimulate and polarize naive T cells, respectively. Furthermore, they acquire a higher cellular motility by upregulating the $\mathrm{C}-\mathrm{C}$ chemokine receptor type 7 that enables DCs to migrate from the periphery to the Tcell areas of draining lymphoid tissues. However, the view that immature DCs induce tolerance and mature DCs induce immunity is simplified. It has been demonstrated that mature DCs can contribute to T-cell tolerance as well [19], suggesting that the maturation trigger dictates the immune functions of the DCs.

2.1.3. Sensitivity. The third reason why DCs are such sophisticated APCs is reflected by the complexity of maturation signals they can detect and respond to [14]. The most important pathways known today are (1) the encounter of microbial agents that trigger surface or intracellular Toll like receptors (TLRs), C type lectin receptors (CLRs), retinoic acid-inducible gene 1 (RIG-I) or nucleotide-binding oligomerization domain (NOD) like receptors [20,21], (2) the direct interaction with cells such as B cells, T cells, natural killer (NK) cells, natural killer T (NKT), and $\gamma \delta \mathrm{T}$ cells, (3) stimulation by cellular products like CD40 ligand (CD40L),
IL- $1 \beta$, TNF $\alpha$, and IL- 6 , and (4) the products of dying cells named damage-associated molecular patterns (DAMPs) like heat shock proteins, high mobility-group box 1 proteins, and uric acid [17]. As distinct antigens are able to trigger DC maturation via one or more of these pathways, this combination serves as a fingerprint that triggers a specific set of receptors $[22,23]$. Subsequently, complex signaling networks are activated which cooperate, integrate and finally converge in the upregulation of distinct transcription factors [24].

A final hallmark of their professionalism is represented by their differential anatomical locations, expression of different markers, distinct antigen processing capacities, and variable responses to maturation stimuli or, in other words, their subdivision in specialized subtypes, as discussed in the next section.

\subsection{Dendritic Cells as a Heterogeneous Population of Subsets.} Given the plethora of antigens, their varied routes of entry into the body, and their diverse characteristics, it is not surprising that a network of professional APCs dedicated to control T-cell immunity diversified to cope with all intruders at all phases of the immune response. About 15 years ago, researchers started to investigate the complexity and merit of the different DC subtypes. However, unraveling this complexity has been complicated in part due to the rarity of DCs in tissues ( $\approx 1 \%$ of cells), their short life span, and their lack of cross-species unifying surface markers. Therefore, the field of DC subtyping came with a lot of observations, hypotheses, and contradictions. However, with the latest ontogenic, phenotypic, and genetic data, it is currently postulated that there are two main "true" DC subtypes in both mice and men: plasmacytoid DCs (pDCs) and conventional DCs (cDCs), which are further subdivided into $\mathrm{cDC1}$ and $\mathrm{cDC} 2$. Below we will elaborate on these subtypes as well as on two cell types that were long considered to be distinct DC subtypes, namely, Langerhans cells (LCs) and monocyte derived DCs (moDCs).

2.2.1. Ontogenic Level. "True" DCs are defined by their fmslike tyrosine kinase 3 ligand- (Flt3-L-) dependent development from hematopoietic stem cells into blood residing precDCs and pDCs [25]. Next, the development of $\mathrm{cDC1}$ is orchestrated by IFN regulatory factor-8 (IRF8), basic leucine zipper ATF-like 3 transcription factor (BATF3), nuclear factor regulated by interleukin-3 (NFIL3), and inhibitor of DNA binding 2 (Id2) [26]. When Id 2 is suppressed by E2-2, pDCs are generated [27]. To differentiate into $\mathrm{cDC} 2$, transcription factors v-rel avian reticuloendotheliosis viral oncogene homolog B (RelB), neurogenic locus notch homolog protein 2 (NOTCH2), recombination signal binding protein for immunoglobulin kappa J region (RBP-J), IRF2, and IRF4 are employed [28]. Although presumed for a very long time, both skin residing LCs and moDCs are not considered "true" DCs since their development is Flt3-L-independent [29]. While circulating monocytes are rapidly mobilized to differentiate into moDCs under inflammatory conditions [30], LCs seem to originate from fetal liver monocytes [31] that require colony stimulating factor 1 receptor (CSF1R) engagement via 
IL-34, which suggests that LCs are more closely related to macrophages [26].

2.2.2. Phenotypic Level. Initially both murine and human cDCs were defined as $\mathrm{CD}_{11 c^{+}} \mathrm{MHC}-\mathrm{II}^{+}$cells located in lymphoid as well as nonlymphoid tissues. Furthermore, cDCs found in lymphoid tissue like bone marrow, spleen, and lymph nodes are called resident DCs and were subdivided into $\mathrm{CD} 8 \alpha^{+}$or $\mathrm{CD} 4^{+} \mathrm{cDC}$ in mice versus $\mathrm{CD} 1 \mathrm{c}(\mathrm{BDCA}-1)^{+}$ or CD141 (BDCA-3) ${ }^{+} \mathrm{cDCs}$ in human. In the nonlymphoid tissues like skin, lungs, and gut, DCs are called migratory since they tend to migrate from peripheral tissues to lymphoid tissue through the lymphatics. In mice, these cDCs are defined to express CD103 or CD11b while, in humans, the same surface markers as in the lymphoid tissues were observed. So while in mice cDCs express different markers in different anatomical locations, human $\mathrm{CD} 141^{+}$DCs and $\mathrm{CD}^{+}{ }^{+}$DCs are abundantly present in both lymphoid and some nonlymphoid tissues such as liver, lung, and skin. Next to the $\mathrm{cDCs}, \mathrm{pDCs}$ are also broadly distributed throughout the body [32]. While mouse $\mathrm{pDCs}$ are $\mathrm{Lin}^{-} \mathrm{MHC}-\mathrm{II}^{+}$and specifically express CD11c, B220 (CD45R), CD317 (BST2), and SiglecH, human pDCs express IL-3R $\alpha$ (CD123), CD303 (BDCA-2), and CD304 (BDCA-4). The murine moDCs express CD11b, CD11c, MHC-II, CD64, and Fc $\gamma$ R $\varepsilon$ alongside varying levels of Ly6C. The human counterparts all express high levels of MHC-II, CD11c, CD11b, CD24, CD1a, and CD206 but lose expression of both macrophage colony stimulating factor (M-CSF) receptor and Ly6C [33]. Of note, an extra subset of human dermal DCs is represented by the $\mathrm{CD}_{1}{ }^{+}$cells which are characterized by their expression of DC-specific ICAM3-grabbing nonintegrin (DC-SIGN), Ctype lectin domain family 1 member (CLEC) 6, lectin-like oxidized LDL receptor-1 (LOX-1), and dectin-1 [34]. Finally, murine LCs characteristically express langerin (CD207), a C type lectin that is localized in LC-specific organelles called Birbeck granules. Human LCs are identified as langerin ${ }^{+}$, $\mathrm{DEC}_{20} 5^{+}, \mathrm{CD} 1 \mathrm{a}^{\mathrm{hi}}$, and CD11c $\mathrm{c}^{\text {lo }}$ (Table 1).

2.2.3. Genetic Level. It became clear that murine lymphoid tissue $\mathrm{CD} 8 \alpha^{+}$and nonlymphoid tissue $\mathrm{CD} 103^{+} \mathrm{cDC}$ subsets as well as the lymphoid tissue $\mathrm{CD} 4^{+}$and nonlymphoid tissue $\mathrm{CD} \mathrm{b}^{+} \mathrm{DC}$ subsets combined constitute two cross-species DC lineages, respectively. Therefore, it was recently proposed to subdivide cDCs into only two main subtypes: one classical type $1 \mathrm{DC}(\mathrm{cDC} 1)$ for murine $\mathrm{CD} 8 \alpha^{+} / \mathrm{CD}_{103}{ }^{+}$and human $\mathrm{CD}_{141^{+}} \mathrm{cDCs}$ [35] and $\mathrm{cDC} 2$ for murine $\mathrm{CD}^{+} / \mathrm{CD}_{11 b}{ }^{+}$ and human $\mathrm{CD}^{+} \mathrm{c}^{+} \mathrm{cDCs}$ (Table 1). Within the $\mathrm{CDCl}$ group, chemokine receptor-1 (XCR1) is emerging as an important cross-species marker, which supports the view that the traditional DC subset markers CD $8 \alpha$ and CD141 are inferior identifiers of the $\mathrm{CDCls}$ and are being superseded by XCR1, CLEC9A (DNGR-1), and cell adhesion molecule 1 (CADM1). Within the $\mathrm{CDC} 2$ group, the most conserved markers are MHC-II ${ }^{\text {hi }}$ and signal-regulatory protein $\alpha\left(\operatorname{SIRP} \alpha^{+}\right)$. The only known pDC-specific conserved markers are IRF7/8 next to TLR7/9 while the conserved markers of LCs are MHC-II, Ecadherin, epithelial cell adhesion molecule (EpCAM), CD11c, and langerin (CD207). Finally, while the human and murine moDCs share the conserved markers MHC-II, CD11b, and CD11c, the human moDCs are further characterized by CD16 and the murine version by Ly6C and DC-SIGN.

2.2.4. Functional Level. Both murine and human $\mathrm{cDC} 1 \mathrm{selec}-$ tively express genes involved in the balance between tolerance and cross-presentation $[36,37]$. They express high levels of MHC-I processing-associated proteins. In addition they possess the dual capacity to produce large amounts of type I IFN and IL-12, making $\mathrm{cDCl}$ ideal stimulators of $\mathrm{CD}^{+}$ cytotoxic T cells (CTLs) [14, 38]. A recent study underlined that only the intratumoral $\mathrm{cDCls}$ were able to facilitate adoptive CTL control of tumor outgrowth [39].

In contrast mouse and human $\mathrm{CDC} 2$ efficiently present antigens to $\mathrm{CD} 4^{+} \mathrm{T}$ cells, favoring their polarization into $\mathrm{T}_{\mathrm{H}} 2$ and $\mathrm{T}_{\mathrm{H}} 17$ cells. They also appear to display a capacity to crosspresent antigens and secrete high levels of IL-12, suggesting a potential key role in promoting IFN $\gamma$ release by NK cells and therefore also $\mathrm{T}_{\mathrm{H}} 1$ polarization [40]. This redundancy for $\mathrm{CDC1}$ and $\mathrm{CDC} 2$ may be a way to allow "mass crosspresentation" as the human $\mathrm{CD}_{141}{ }^{+} \mathrm{cDC1}$ represent only a small fraction $(\approx 2 \%)$ of all DCs, at least in blood [41].

The pDCs are best known for their ability to produce high amounts of type I IFN (IFN $\alpha$ and IFN $\beta$ ) in response to viral stimuli and as such control the progress of viral infections at various levels [42]. In their resting state, however, $\mathrm{pDCs}$ play an important role in the induction of tolerance owing to a low expression of MHC and costimulatory molecules compared to their $\mathrm{CDC}$ counterparts. However, in humans this view has been challenged by recent findings that metastatic melanoma patients receiving intranodal injections of activated and peptide loaded $\mathrm{pDCs}$ were very effective at inducing potent antitumor immunity [43].

MoDCs are a special type of subset since they are created according to the type of inflammation. In general, moDCs capture antigen and migrate to the draining lymphoid tissues to predominantly drive $\mathrm{T}_{\mathrm{H}} 1$ or $\mathrm{T}_{\mathrm{H}} 17 \mathrm{immunity}$ by producing IL-12 or IL-23, respectively. After infection they can also produce TNF $\alpha$ and inducible nitric oxide synthase (iNOS). Furthermore, they seem to be evolved as a crucial reservoir of APCs with a potent emergency backup role in cases of acute inflammation [30].

Finally the murine epidermal LCs are an atypical APC subset that seems specialized in the uptake and processing of antigens in the periphery for peripheral tolerance induction, especially during steady state conditions. In addition, they can produce IL-23, IL- 6 , and IL- $1 \beta$ during inflammation. On the contrary, human LCs have been described to induce robust proliferation of naive allogeneic $\mathrm{CD}^{+} \mathrm{T}$ cells far more efficient than the $\mathrm{CD}_{1}{ }^{+}$DCs through the secretion of IL-15 which promotes the differentiation of granzyme $\mathrm{B}^{+} /$perforin ${ }^{+}$CTLs. Moreover, they appear to be efficient at cross-presenting peptides [44]. In general, the role of LCs seems to be dictated by environmental cues, rather than a preimprinted behavior.

In summary every DC subset has its own functional specialties, which opened up exciting possibilities for targeted manipulation to tune the immune response by harnessing 
TABLE 1: Concise overview of the ontogenic, phenotypic, and functional features of the five main DC subtypes: $\mathrm{cDC1}, \mathrm{cDC} 2, \mathrm{pDC}, \mathrm{LC}$, and moDC.

\begin{tabular}{|c|c|c|c|c|c|}
\hline & $\mathrm{cDC1}$ & $\mathrm{cDC} 2$ & $\mathrm{pDC}$ & LC & moDC \\
\hline Ontogeny & $\begin{array}{c}\text { HSC + Flt3-L, } \\
\text { BATF3, NFIL3, and } \\
\text { Id2 }\end{array}$ & $\begin{array}{c}\text { HSC + Flt3-L, RelB, } \\
\text { NOTCH2, RBP-J, } \\
\text { IRF2, and IRF4 }\end{array}$ & $\begin{array}{c}\mathrm{HSC}+\text { Flt3-L and } \\
\text { E2-2 }\end{array}$ & $\begin{array}{c}\text { Blood residing } \\
\text { monocytes }+ \\
\text { inflammation }\end{array}$ & $\begin{array}{c}\text { Fetal liver } \\
\text { monocytes }+ \\
\text { CSF1R }\end{array}$ \\
\hline $\begin{array}{l}\text { Mouse } \\
\text { Other markers }\end{array}$ & $\begin{array}{c}\mathrm{CD} 8 \alpha^{+} / \mathrm{CD} 103^{+} \mathrm{cDC} \\
\mathrm{DEC} 205^{+}\end{array}$ & $\mathrm{CD}^{+} \mathrm{CD}^{-11 b^{+} \mathrm{cDC}}$ & $\begin{array}{c}\text { SiglecH }^{+} \mathrm{BST}^{+} \\
\mathrm{B} 220^{+}\end{array}$ & Langerin $^{+}$LC & $\begin{array}{c}\mathrm{CD}_{11 \mathrm{~b}^{+} \text {moDCs }} \\
\mathrm{CD} 64, \mathrm{Fc} \gamma \mathrm{R} \varepsilon \text {, and } \\
\text { Ly6c }\end{array}$ \\
\hline $\begin{array}{l}\text { Human } \\
\text { Other markers }\end{array}$ & $\begin{array}{c}\mathrm{CD} 141^{+} \mathrm{cDC} \\
\mathrm{CD} 162^{\mathrm{hi}} \mathrm{DEC} 205^{\mathrm{hi}}\end{array}$ & $\begin{array}{l}\mathrm{CD}^{+} \mathrm{c}^{+} \mathrm{cDC} \\
\mathrm{CD}_{11 \mathrm{~b}}^{\mathrm{lo} /+}\end{array}$ & 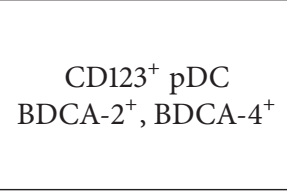 & $\begin{array}{c}\text { Langerin }^{+} \text {LC } \\
\text { DEC205, CD1a }\end{array}$ & $\begin{array}{c}\mathrm{CD}_{11 b^{+}} \mathrm{CD}_{1}{ }^{+} \\
\mathrm{moDCs}^{+} \\
\mathrm{CD} 24^{+}, \mathrm{CD} 206^{+}, \\
\mathrm{CD} 16^{+}, \text {and } \\
\text { DC-SIGN }\end{array}$ \\
\hline $\begin{array}{l}\text { Conserved } \\
\text { (besides CD11c and } \\
\text { MHC class II) }\end{array}$ & $\begin{array}{l}\mathrm{TLR}^{+}{ }^{+} \mathrm{CADM}^{+} \\
\mathrm{XCR}^{+}{ }^{+} \mathrm{CLEC}^{+}{ }^{+}\end{array}$ & $\mathrm{MHCII}^{\mathrm{hi}} \operatorname{SIRP} \alpha^{+}$ & TLR7 $^{\text {hi }}$ TLR $^{\text {hi }}$ & $\begin{array}{c}\text { E-cadherin }{ }^{+}, \\
\text {EpCAM }^{+} \text {, and } \\
\text { langerin }\end{array}$ & $\mathrm{CD}_{11 \mathrm{~b}^{+}}$ \\
\hline Functions & $\begin{array}{c}\mathrm{T}_{\mathrm{H}} 1 \\
\text { Cross-presentation }\end{array}$ & $\begin{array}{c}\mathrm{T}_{\mathrm{H}} 2 \text { and } \mathrm{T}_{\mathrm{H}} 17 \\
\text { Cross-presentation }\end{array}$ & $\begin{array}{c}\text { IFN- } \alpha / \beta \text { and IFN } \lambda \\
\text { Humoral }\end{array}$ & $\begin{array}{c}\text { Adaptable } \\
\text { MOUSE: Treg or } \mathrm{T}_{\mathrm{H}} 17 \\
\text { HUMAN: IL-15 } \\
\text { promoting CTLs + } \\
\text { Cross-presentation }\end{array}$ & $\begin{array}{l}\text { Highly adaptable } \\
\text { (IL-12, IL-23, } \\
\text { TNF } \alpha \text {, and iNOS) }\end{array}$ \\
\hline
\end{tabular}

subset specific attributes. Subsequently antitumor vaccination became not only a question of proper DC activation but also of selecting the most appropriate DC subtype [34, 44].

\section{How Can Antigen-Presenting Cell Subsets Be Targeted?}

In general every active antitumor vaccine needs to comprise both a TAA and an appropriate stimulus to avoid the induction of TAA specific tolerance. In terms of vaccination modalities, we can roughly subdivide them in four groups: naked protein based, naked nucleic acid based, viral vector based, and nanoparticle based vaccines [40, 45-48]. In general, both naked protein and nucleic acid based vaccines are relatively easy to generate. However, they always need to be codelivered with an adjuvant to achieve robust antitumor immunity. On the contrary, viral vectors and nanoparticles are intrinsically immunogenic as they have a pathogen-like size and appearance. Moreover, when in vivo vaccination of mice with a viral vector was compared to peptide, DNA, or DC vaccination, stronger tumor specific immune responses were elicited with viral vectors [49-51]. As antitumor vaccines have been developed in numerous shapes and sizes, their extent of targeting possibilities is very diversified as well. In this section we will discuss the three main targeting approaches while a detailed overview of the performed preclinical and clinical in vivo APC targeting experiments in the framework of antitumor immunotherapy is summarized in Table 2.

3.1. Administration Based Targeting. After antigen delivery the so-called "depot-effect" tends to retain most of the antigen at the injection site. To increase vaccine uptake by APCs, the most straightforward way is represented by vaccine delivery into an APC rich site such as the tumor draining lymph node or spleen. For example, when we delivered TAA encoding lentiviral vectors (LVs) or mRNA intranodally in mice, a stronger therapeutic $\mathrm{CD}^{+} \mathrm{T}$-cell response was induced than after subcutaneous delivery $[45,52]$. Alternatively vaccines can be developed in such a way that they become prone to accumulation in lymphoid organs [53-55]. The latter is exemplified by two different studies in tumor bearing mice with nanoparticles (NPs) coupled to adjuvant alone or also a TAA. The NPs accumulated in the tumor draining lymph nodes when intradermally administered in the limb ipsilateral to the tumor or in the nontumor draining lymph node when administered in the contralateral limb. Interestingly, only when these NPs were targeted to the tumor draining lymph node, the $\mathrm{CD} 4^{+}$T-cell distribution within the tumor repolarized towards a $\mathrm{T}_{\mathrm{H}} 1$ phenotype and an increased frequency of therapeutic antigen-specific $\mathrm{CD}^{+} \mathrm{T}$ cells within the tumor was observed. Together, these data implicate that the tumor draining lymph node is an appealing vaccine target for solid tumors and can be targeted with NPs [56-58]. Of note also skin DC networks have been targeted via the use of polymeric dissolving microneedle arrays with nanoencapsulated antigen $[59,60]$.

Recently, intratumoral administration of antitumor vaccines has emerged [61]: on the one hand because numerous vaccination studies showed the induction of potent TAAspecific T-cell responses without clear therapeutic benefit [62] and on the other hand because the tumor microenvironment turns out to be a very manipulative system that is able to protect tumor cells from a cytotoxic attack and moreover help in tumor progression. Noteworthy in this process are the regulatory myeloid cells, represented by myeloid derived suppressor cells, type 2 or N2 tumor associated neutrophils, a subset of mast cells, M2 macrophages, and regulatory tumor associated DCs [63]. Although the latter two could 
TABLE 2: Summary of in vivo APC targeting studies in the framework of antitumor vaccination.

\begin{tabular}{|c|c|c|c|c|}
\hline Targeting moiety & Injection & Content & Effect & References \\
\hline \multicolumn{5}{|c|}{ CLR } \\
\hline $\begin{array}{l}D E C 205 \\
\alpha \text {-GalCer NP }\end{array}$ & $\mathrm{fp}$ & OVA & $\begin{array}{l}\uparrow \text { iNKT, } \downarrow \text { growth in B16F10, and } \\
\text { EG7-OVA }(\mathrm{P}+\mathrm{T})\end{array}$ & {$[147]$} \\
\hline Selected nucleic acid aptamer & i.v. & OVA & $\begin{array}{l}\uparrow C D 8, \downarrow \text { growth OVA-B16 tumor } \\
\text { (T if OT-I transfer) }\end{array}$ & {$[95]$} \\
\hline $\begin{array}{l}\text { Anti-CD11c and DEC205 scFv } \\
\text { coupled to NP }\end{array}$ & i.v. & $\mathrm{OVA}+\mathrm{ADJ}$ & $\begin{array}{l}\uparrow C D 8, \downarrow \text { growth OVA-B16 tumor } \\
\text { (P) }\end{array}$ & {$[83]$} \\
\hline $\mathrm{mAb}$ fused protein & s.c. & $\mathrm{OVA}+\mathrm{ADJ}$ & $\uparrow C D 8, \downarrow$ growth OVA-B16 $(\mathrm{P}+\mathrm{T})$ & {$[131]$} \\
\hline $\mathrm{mAb}$ fused protein & i.p. & HER2 + ADJ & $\begin{array}{l}\uparrow \mathrm{CD} 8, \uparrow \mathrm{CD} 4, \uparrow \text { humoral, and } \\
\text { \growth neu-expressing } \\
\text { mammary tumor }(\mathrm{P})\end{array}$ & {$[148,149]$} \\
\hline $\mathrm{mAb}$ fused protein & i.p. & Mesothelin + ADJ & $\begin{array}{l}\uparrow \text { cross-presentation, } \uparrow \mathrm{CD} 4 \text {, } \\
\uparrow \text { humoral, and } \downarrow \text { growth } \\
\text { neu-expressing mammary tumor } \\
\text { (P) }\end{array}$ & {$[150]$} \\
\hline scFV modified adenoviral vector & $\mathrm{fp}$ & OVA & $\begin{array}{l}\uparrow \mathrm{T} \text { cell, } \uparrow \text { humoral (at low doses), } \\
\downarrow \text { growth OVA-B16 (P) BUT } \\
\text { better for untargeted vectors }\end{array}$ & {$[127]$} \\
\hline $\mathrm{mAb}$ fused protein & $\mathrm{fp}$ & $\mathrm{OVA}+\mathrm{ADJ}$ & $\begin{array}{l}\uparrow \mathrm{CD} 8, \downarrow \text { growth } \mathrm{B} 16 \\
\text { pseudo-metastasis model }(\mathrm{P}+\mathrm{T})\end{array}$ & {$[120]$} \\
\hline Bacteriophage displaying scFV & $\mathrm{fp}$ & OVA & \growth B16F10 (Pro + Ther) & {$[151]$} \\
\hline $\mathrm{mAb}$ fused protein & s.c. & Trp2 and gp100 + ADJ & $\begin{array}{l}\uparrow \mathrm{CD} 8, \uparrow \mathrm{CD} 4 \text {, and } \downarrow \text { growth } \mathrm{B} 16 \\
\text { melanoma }(\mathrm{P}+\mathrm{T})\end{array}$ & {$[152]$} \\
\hline scFV fused to DNA vaccine & i.m. & Her2/neu + CPM & $\begin{array}{l}\uparrow \text { CD8, } \uparrow \text { humoral, long lasting } \\
\text { memory } \downarrow \text { growth HER } 2 / \text { neu }^{+} \\
\text {D2F2/E2 breast tumor }+ \\
\text { spontaneous mammary } \\
\text { carcinomas }(P+T)\end{array}$ & {$[153]$} \\
\hline $\begin{array}{l}\text { Phase I clinical trial with } \\
\text { CDX-1401 = human } \mathrm{mAb} \text { fused } \\
\text { protein }\end{array}$ & i.d. & NY-ESO-1 + ADJ & $\begin{array}{l}\text { Patients with advanced } \\
\text { malignancies: } \uparrow \text { cellular, } \\
\uparrow \text { humoral (T) }\end{array}$ & {$[154]$} \\
\hline $\begin{array}{l}\text { DEC206 } \\
\text { Mannosylated NP }\end{array}$ & s.c. & $\mathrm{OVA}+\mathrm{ADJ}$ & $\begin{array}{l}\uparrow \mathrm{T}_{\mathrm{H}} 1 \text { cell, } \uparrow \text { humoral, and } \\
\downarrow \text { growth } \mathrm{B} 16 \mathrm{~F} 10(\mathrm{P}+\mathrm{T})\end{array}$ & {$[155]$} \\
\hline $\mathrm{mAb}$ fused to protein & s.c. & $\mathrm{OVA}+\mathrm{ADJ}$ & $\begin{array}{l}\uparrow T \text { cell, } \uparrow \text { humoral, and } \downarrow \text { growth } \\
\text { B11-OVA (P) }\end{array}$ & {$[156]$} \\
\hline Mannan coupled protein & i.p. & MUC-1 & $\begin{array}{l}\uparrow \mathrm{CD} 8, \downarrow \text { growth P815 } \\
\text { mastocytoma }(\mathrm{T})\end{array}$ & {$[157]$} \\
\hline Mannose coupled dendrimer & i.d. & OVA & $\begin{array}{l}\uparrow \mathrm{CD} 8, \uparrow \mathrm{CD} 4, \uparrow \text { humoral, } \\
\downarrow \text { growth B16-OVA (P) }\end{array}$ & {$[158]$} \\
\hline Mannosylated NP & s.c. & ErbB2/HER3 + ADJ & $\begin{array}{l}\downarrow \text { growth huErbB2 }{ }^{+} \text {renal } \\
\text { carcinoma cells }(\mathrm{T})\end{array}$ & {$[125]$} \\
\hline $\begin{array}{l}\text { Mannan coated } \\
\text { liposome-protamine-DNA }\end{array}$ & $\mathrm{U}$ & HPV16 E7 & $\downarrow$ growth $\mathrm{E}^{+} \mathrm{TC}-1(\mathrm{P}+\mathrm{T})$ & {$[159]$} \\
\hline $\begin{array}{l}\text { Mannosylated and/or histidylated } \\
\text { NP loaded with mRNA }\end{array}$ & i.v. & MART-1 & $\uparrow \mathrm{CD} 8, \downarrow$ growth B16F10 (P) & {$[160,161]$} \\
\hline $\begin{array}{l}\text { Mannan or pullulan NP complexed } \\
\text { with protein }\end{array}$ & $\mathrm{U}$ & HER2 & $\begin{array}{l}\uparrow \mathrm{CD} 8, \downarrow \text { growth } \mathrm{HER} 2^{+} \text {tumors } \\
(\mathrm{P}+\mathrm{T})\end{array}$ & {$[162]$} \\
\hline $\begin{array}{l}\text { D-mannose conjugated lipid-core } \\
\text { peptide system }\end{array}$ & s.c. & HPV16 E7 & $\downarrow$ growth TC-1 HPV-16 tumor (P) & {$[163]$} \\
\hline $\begin{array}{l}\text { Clinical trial with mannan } \\
\text { coupled protein }\end{array}$ & s.c. & MUC-1 & $\begin{array}{l}\uparrow \text { humoral, less } \uparrow \mathrm{CD} 8, \\
\text { protection against recurrence } \\
\text { in breast cancer patients }\end{array}$ & [106] \\
\hline
\end{tabular}


TABLe 2: Continued.

\begin{tabular}{|c|c|c|c|c|}
\hline Targeting moiety & Injection & Content & Effect & References \\
\hline $\begin{array}{l}\text { Two phase I studies with } \\
\text { CDX-1307 = hCG- } \beta \text { fused to mAb }\end{array}$ & i.d. or i.v. & hCG- $\beta+$ ADJ & $\begin{array}{l}\uparrow \text { humoral and } T \text { cell with } \\
\text { clinical benefit in patients with } \\
\text { advanced epithelial } \\
\text { malignancies }\end{array}$ & {$[164]$} \\
\hline $\begin{array}{l}\text { DC-SIGN } \\
\text { LV pseudotyped with } \\
\text { point-mutated Sindbis virus } \\
\text { glycoprotein }\end{array}$ & i.d. & OVA or PSCA & $\begin{array}{l}\uparrow \mathrm{CD} 8, \uparrow \mathrm{CD} 4 \text {, and } \downarrow \text { growth } \\
\text { transgenic adenocarcinoma, } \\
\text { E.G7-OVA and PSCA-expressing } \\
\text { B16-F10 }(\mathrm{P}+\mathrm{T})\end{array}$ & {$[5,103,165]$} \\
\hline mAb coupled protein & $\mathrm{U}$ & $\mathrm{KLH}$ & $\begin{array}{l}\downarrow \text { growth human Burkitt’s } \\
\text { lymphoma cell line in humanized } \\
\text { mice (P) }\end{array}$ & {$[166]$} \\
\hline $\begin{array}{l}\text { IDLV pseudotyped with engineered } \\
\text { Sindbis virus glycoprotein }+ \\
\text { currently tested in Phase I clinical } \\
\text { trial ID-VP02 }\end{array}$ & s.c. & NY-ESO + Vpx & $\begin{array}{l}\uparrow C D 8, \downarrow \text { growth CT26 colon } \\
\text { carcinoma cells }(\mathrm{P}+\mathrm{T})\end{array}$ & {$[167,168]$} \\
\hline $\begin{array}{l}L O X-1 \\
\text { HSP70 fused to protein }\end{array}$ & s.c. & OVA & $\begin{array}{l}\uparrow \mathrm{CD} 8 \text { and cross-priming, } \\
\downarrow \text { growth E.G7 cells }(\mathrm{P})\end{array}$ & {$[169]$} \\
\hline $\begin{array}{l}\text { CLEC9A } \\
\text { mAb coupled to peptide }\end{array}$ & s.c. & MUC-1 + ADJ & $\begin{array}{l}\uparrow \mathrm{T}_{\mathrm{H}} 1, \downarrow \text { growth MUC-1-A2K/b } \\
\text { MC38 }(\mathrm{P}+\mathrm{T})\end{array}$ & {$[170]$} \\
\hline mAb coupled to peptide & s.c. & OVA + ADJ & $\begin{array}{l}\uparrow C D 8, \downarrow \text { growth B16 lung pseudo } \\
\text { metastases }(P+T)\end{array}$ & {$[138]$} \\
\hline $\begin{array}{l}\text { DCIR2 } \\
\text { Anti-DCIR2 or anti-DEC205 mAb } \\
\text { coupled protein }\end{array}$ & i.p. & $\mathrm{OVA}+\mathrm{ADJ}$ & $\begin{array}{l}\uparrow \mathrm{CD} 8, \uparrow \mathrm{CD} 4\left(\text { mixed } \mathrm{T}_{\mathrm{H}} 1 / \mathrm{T}_{\mathrm{H}} 2\right), \\
\uparrow \text { humoral, and } \downarrow \text { growth } \\
\text { B16F10-OVA }(\mathrm{P}+\mathrm{T})\end{array}$ & {$[171]$} \\
\hline \multicolumn{5}{|c|}{ Integrin } \\
\hline $\begin{array}{l}\text { CD11c } \\
\text { Targeted lipopeptide }\end{array}$ & i.d. & OVA, WT1, tumor lysate + ADJ & $\begin{array}{l}\downarrow \text { growth for OVA: E.G7-OVA, for } \\
\text { mWT1: mWT1-1498 cells and for } \\
\text { tumor lysate: MHC-I }{ }^{-} \text {B16D8 } \\
\text { melanoma (T) }\end{array}$ & {$[172]$} \\
\hline $\begin{array}{l}\text { Tumor-derived plasma membrane } \\
\text { vesicles engrafted with two CD1lc } \\
\text { binding peptides }\end{array}$ & i.v. & OVA & $\begin{array}{l}\uparrow \mathrm{CD} 8, \uparrow \text { humoral, and } \downarrow \text { growth of } \\
\text { metastatic B16-OVA ( } \mathrm{T} \text { ) }\end{array}$ & {$[173]$} \\
\hline $\begin{array}{l}\text { CD11b } \\
\text { Adenylate cyclase- } \\
\text { (CyaA-) based vector }\end{array}$ & i.p. vs. i.v. or i.d. & OVA vs. HPV E7 & $\begin{array}{l}\downarrow \text { growth OVA-B16 or E.G7-OVA } \\
\text { versus TC-1 }(\mathrm{P}+\mathrm{T})\end{array}$ & {$[113,174]$} \\
\hline $\begin{array}{l}\text { Phase II study with ProCervix = } \\
\text { CyaA-based vector }\end{array}$ & s.c. & HPV16 and 18 E7 + ADJ & $\begin{array}{l}\text { Clinical phase I trial indicated } \\
\text { good safety and local tolerance } \\
\text { at the highest dose, } \uparrow \mathrm{T}+\uparrow \text { viral } \\
\text { clearance }+ \text { controlled HPV } \\
\text { recurrence }\end{array}$ & NCT01957878 \\
\hline \multicolumn{5}{|c|}{ Fc $\gamma$ receptor } \\
\hline IgG1-Fc tumor cells & s.c. & TAAs & $\downarrow$ growth E.G7 $(\mathrm{P}+\mathrm{T})$ & {$[175]$} \\
\hline HER2-Fc cDNA & i.m. + EP & HER2 & $\begin{array}{l}\mathrm{Mu}: \uparrow \mathrm{T}, \downarrow \text { growth } \mathrm{HER}^{+} \\
\mathrm{D} 2 \mathrm{~F} 2 / \mathrm{E} 2 \text { cells }(\mathrm{P}) \\
\text { Hu: } \text { in } \text { vitro cross-processing } \\
\text { and } \uparrow \mathrm{CD8}^{+} \mathrm{T} \text { cells from breast } \\
\text { cancer patients }\end{array}$ & [176] \\
\hline \multicolumn{5}{|c|}{ MHC-II molecule } \\
\hline $\begin{array}{l}\text { DNA loaded dendrimer with } \\
\text { targeting peptide }\end{array}$ & s.c. & Trp2 or gp70 vs. OVA & $\begin{array}{l}\uparrow \mathrm{CD} 8, \uparrow \text { humoral, } \downarrow \text { growth, } \\
\text { strong for B16OVA, and weak for } \\
\text { gp70 BUT better with EP }(\mathrm{P}) \leftrightarrow \\
\text { B16 with Trp2 }(\mathrm{T})\end{array}$ & {$[177]$} \\
\hline $\begin{array}{l}\text { LV pseudotyped with scFv coupled } \\
\text { to } \mathrm{H} \text { protein of measles virus } \\
\text { envelope }\end{array}$ & i.v. & OVA or male HY gene & $\begin{array}{l}\uparrow C D 4, \uparrow \text { cytotoxic, and memory } \\
\text { CD8 BUT not to the same extent } \\
\text { as broad tropism LVs }\end{array}$ & {$[112,178]$} \\
\hline $\begin{array}{l}\text { LV pseudotyped with scFV coupled } \\
\text { to murine leukemia virus envelope }\end{array}$ & s.c. & OVA & $\uparrow \mathrm{CD} 8$ mediated IFN $\gamma$ secretion & [179] \\
\hline
\end{tabular}


TABLE 2: Continued.

\begin{tabular}{|c|c|c|c|c|}
\hline Targeting moiety & Injection & Content & Effect & References \\
\hline $\begin{array}{l}\text { DNA encoding anti-MHC II and } \\
\text { anti-CD40 scFv or chemokines } \\
\text { (MIP- } 1 \alpha \text {, RANTES) with scFV of } \\
\text { idiotype }\end{array}$ & i.m. or i.d. + EP & Idiotypes & $\begin{array}{l}\uparrow \mathrm{CD} 8, \uparrow \text { humoral, and } \downarrow \text { growth } \\
\mathrm{Id}^{+} \text {tumors }(\mathrm{P})\end{array}$ & {$[180,181]$} \\
\hline \multicolumn{5}{|c|}{ Non-CLR surface marker } \\
\hline $\begin{array}{l}\text { BST2 } \\
\text { Protein fused anti-BST2 Ab }\end{array}$ & i.p. & OVA or $\mathrm{pHEL}+\mathrm{ADJ}$ & $\begin{array}{l}\uparrow \mathrm{CD} 4, \uparrow \mathrm{CD} 8, \uparrow \text { humoral + } \\
\downarrow \text { growth B16-OVA }(\mathrm{P})\end{array}$ & {$[182]$} \\
\hline \multicolumn{5}{|c|}{ Undefined } \\
\hline $\begin{array}{l}\text { NP with cholesteryl pullulan } \\
\text { towards medullary macrophages }\end{array}$ & s.c. & MAGE-A4 or mERK2 + ADJ & 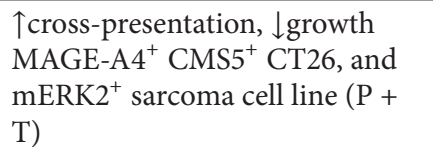 & {$[183]$} \\
\hline $\begin{array}{l}\text { Listeria monocytogenes expressing } \\
\text { TAAs }\end{array}$ & i.p. & VEGFR2 + ADJ & $\begin{array}{l}\uparrow C D 8 \text { with epitope spreading, } \\
\downarrow \text { growth breast tumors }(\mathrm{P}+\mathrm{T})\end{array}$ & {$[114,184]$} \\
\hline Coronavirus vector & i.v. & MelanA or Gp33 + ADJ & $\begin{array}{l}\uparrow C D 8 \text {, expanded epitope } \\
\text { repertoire, growth Melan } A^{+} \text {or } \\
\text { gp } 33^{+} \text {B16F10 }(\mathrm{P}+\mathrm{T})\end{array}$ & {$[185,186]$} \\
\hline $\begin{array}{l}\text { APC specific nanobody displaying } \\
\text { LV }\end{array}$ & i.n. & OVA & $\begin{array}{l}\uparrow \mathrm{CD} 4, \uparrow \mathrm{CD} 8, \downarrow \text { growth }(\mathrm{T}) \mathrm{BUT} \\
\text { not to the same extent as broad } \\
\text { tropism LVs }\end{array}$ & {$[45]$} \\
\hline ISCOM vaccine & s.c. & OVA & $\begin{array}{l}\uparrow C D 8, \downarrow \text { growth EG-7-, B16-, or } \\
\text { Panc-OVA (P) }\end{array}$ & [187] \\
\hline \multicolumn{5}{|c|}{ Costimulatory molecule } \\
\hline $\begin{array}{l}\text { CD40 } \\
\text { PLGA-NP coated with mAb }\end{array}$ & s.c. & OVA and E7 + ADJ & $\begin{array}{l}\uparrow \mathrm{CD} 8, \uparrow \mathrm{CD} 4+\downarrow \text { growth } \\
\text { B16-OVA }(\mathrm{P}+\mathrm{T})\end{array}$ & {$[188]$} \\
\hline CD40 targeted adenoviral vector & i.p. & PSMA + ADJ & $\begin{array}{l}\uparrow \mathrm{CD} 8, \downarrow \text { growth RM-1-PSMA } \\
\text { model (T) }\end{array}$ & [189] \\
\hline $\begin{array}{l}\text { CD40L extracellular domain to } \\
\text { adenoviral vector in mice }+ \\
\text { Clinical trial }\end{array}$ & i.d. & $\begin{array}{l}\text { Mice: Trp2 or gp100 } \\
\text { Human: MART-1 }\end{array}$ & $\begin{array}{l}\text { Mice: } \uparrow \mathrm{CD} 8, \downarrow \text { growth } \mathrm{B} 16 \mathrm{~F} 10(\mathrm{~T}) \\
\uparrow \mathrm{CD8} \text { in melanoma-draining } \\
\text { sentinel lymph nodes }\end{array}$ & {$[190,191]$} \\
\hline $\begin{array}{l}\text { B7 } \\
\text { Syngeneic epithelial cells } \\
\text { continuously secreting } \\
\text { CTLA-4-ErbB2 fusion vaccine }\end{array}$ & s.c. & HuErbB2 + IL-15 & $\begin{array}{l}\uparrow \mathrm{CD} 8, \uparrow \text { humoral, } \downarrow \text { growth } \\
\text { ErbB2 }^{+} \text {renal cell carcinoma }(\mathrm{T})\end{array}$ & [192] \\
\hline $\begin{array}{l}\text { Treml4, Ig superfamily member } \\
\text { mAb against Treml } 4\end{array}$ & i.p. & OVA or HER $2+\mathrm{ADJ}$ & $\begin{array}{l}\uparrow C D 8, \uparrow C D 4, \downarrow \text { growth neu }{ }^{+} \\
\text {mammary tumor cell line NT2.5 } \\
(\mathrm{P})\end{array}$ & [193] \\
\hline $\begin{array}{l}\text { TLRs } \\
\text { TLR9 targeting protein (via DNA } \\
\text { sequence) }\end{array}$ & i.d. & $\mathrm{OVA}+\mathrm{CpG}$ & $\begin{array}{l}\mathrm{T}_{\mathrm{H}}-\text { independent } \uparrow \mathrm{CD} 8+ \\
\downarrow \text { growth E.G7-OVA }(\mathrm{P}+\mathrm{T})\end{array}$ & [194] \\
\hline $\begin{array}{l}\text { TLR2 targeting lipid moiety + } \\
\text { epitopes }\end{array}$ & s.c. & OVA & $\begin{array}{l}\uparrow C D 8, \uparrow \text { humoral }+\downarrow \text { growth } \\
\text { B16-OVA, and Lewis lung-OVA } \\
(\mathrm{P}+\mathrm{T})\end{array}$ & [195] \\
\hline $\begin{array}{l}\text { TLR } 5 \text { targeted peptides (via } \\
\text { flagellin) engrafted onto liposomes }\end{array}$ & i.v. & OVA & $\begin{array}{l}\uparrow \text { maturation of DCs, } \uparrow \text { CD8, } \\
\uparrow \text { humoral, } \downarrow \text { growth B16, and } \\
\text { P815 }(\mathrm{P}+\mathrm{T})\end{array}$ & {$[173,196]$} \\
\hline $\begin{array}{l}\text { TLR4 targeting protein (via } \\
\text { fibronectin) }\end{array}$ & i.t. or i.v. & HPV E7 w or w/o ADJ or CPM & $\begin{array}{l}\uparrow C D 8 \text { with cure of established } \\
\text { TC- } 1 \text { tumors } \\
\text { i.t.: in the absence of additional } \\
\text { ADJ } \\
\text { i.v.: when + ADJ or CPM + ADJ }\end{array}$ & [197] \\
\hline $\begin{array}{l}\text { TLR4 targeting protein (via } \\
\text { fibronectin) + anti-CD40, TLR3 and } \\
\text { TLR7 ligands }\end{array}$ & s.c. & $\mathrm{OVA}+\mathrm{ADJ}$ & $\begin{array}{l}\uparrow \mathrm{CD} 8, \downarrow \text { growth B16-OVA or } \\
\text { B16.F10 (T) }\end{array}$ & [198] \\
\hline
\end{tabular}


TABLE 2: Continued.

\begin{tabular}{|c|c|c|c|c|}
\hline Targeting moiety & Injection & Content & Effect & References \\
\hline $\begin{array}{l}\text { Chemokine related } \\
\text { Fusion of chemokine MCP3 or IP10 } \\
\text { to lymphoma-derived scFv as } \\
\text { protein or DNA plasmid }\end{array}$ & s.c. or i.d. & $\mathrm{scFV}$ & $\begin{array}{l}\text { } \text { humoral, } \downarrow \text { growth } 38 \mathrm{C}-13 \text { and } \\
\text { A20 (P) }\end{array}$ & [199] \\
\hline $\begin{array}{l}\text { OVA with mAb or chemokine } \\
\text { ligand XCL1 against XCR1 }\end{array}$ & i.v. & $\mathrm{OVA}+\mathrm{ADJ}$ & $\uparrow \mathrm{CD} 8, \downarrow$ growth E.G7 (P) & {$[200]$} \\
\hline
\end{tabular}

be potent antigen presenters of the TAAs they capture in their surroundings, the tolerogenic microenvironment squeezes them into a suppressive state. Interestingly, since they retain a highly plastic phenotype, it seems possible to reprogram them towards potent antitumor immunity stimulating APCs. Therefore, our understanding is shifting emphasis from targeting APCs within the draining lymphoid organs by intranodal injection or lymph node targeted NPs to reprogramming APCs within the tumor microenvironment by intratumoral injection [64].

While administration based targeting is a very straightforward way to increase the chance that APCs are stimulated, it does not allow APC subtype specific targeting. Therefore, other targeting approaches have been developed as discussed in the following paragraphs.

3.2. Expression Based Targeting. When a nucleic acid based vaccine is administered, the expression of the encoded TAAs is most often driven by a strong constitutive promoter with or without enhancer sequences. These include the cytomegalovirus, spleen focus forming virus, human polypeptide chain elongation factor- $1 \alpha$, phosphoglycerate kinase, and ubiquitin C promoters [65-67]. Although these promoters induce strong and ubiquitous expression of the transgene, they are (1) more prone to promoter inactivation than cell specific promoters, (2) more potent in activating the host-cell defense machinery, and (3) increasing the potential risk of insertional mutagenesis caused by their enhancer sequences $[68,69]$. These downsides resulted in the development of various strategies to allow APC-specific transgene expression by incorporating cell type specific regulatory elements and/or promoter(s) in the expression cassette [70, 71]. Examples are the CD11c, DC-SIGN, DCSTAMP, langerin, HLA-DR, MHC-II, and dectin-2 promoter [72-75]. However, DC specific transgene expression does not guarantee a strong CTL response, since DC specific promoters have also been applied to induce transgene specific tolerance $[76,77]$. Furthermore, it has been described that tissue specific promoters may still be active in many different cell types or states since the promoter is used outside its normal genomic context [78]. Moreover, transcriptional targeting does not reduce the possible risk for insertional mutagenesis nor the possibility of cargo transfer to germ line cells [79]. Due to these conflicting outcomes, more research needs to be done on the immune stimulatory potential of APC specific promoter driven antitumor vaccines.
3.3. Cell Entry Based Targeting. Cell entry based targeting exploits APC specific surface receptors to target a particular APC subtype and mediate vaccine internalization [80]. Robustly, five main APC specific receptor families have been evaluated for targeting: the CLR family, integrins, $\mathrm{Fc} \gamma$ receptors, $\mathrm{MHC}$-II molecules, and immune stimulating receptors. Of these, CLRs have been the focus of most APC targeted research in mice, nonhuman primates, and humans (Table 2) [81, 82]. Typically CLRs recognize carbohydrate structures in a calcium-dependent manner and are as such involved in the recognition and internalization of many glycosylated selfantigens and pathogens. Subsequently, CLRs can facilitate antigen uptake, processing, antigen routing, and MHC-I and -II loading. Furthermore, we depict in Table 2 all non-CLR, noncostimulatory molecular targets, as well as costimulatory molecules, used to restrict antigen delivery to APCs on the one hand and license the APC on the other hand. In general, studies regarding the most suited receptor for the induction of potent antitumor immunity remain thus far very contradictory. For example, when mice were immunized with liposomes coupled to single chain $\mathrm{Ab}$ fragments ( $\mathrm{scFv}$ ) against CD11c or DEC205, the latter performed twice as good [83]. In contrast, it has also been shown that CD11c targeting was better than targeting CD205, MHC-II, CD11a, CD11b, DCIR2, or CD40 in terms of cellular and humoral immunity [40].

Because receptor ligation influences intracellular vaccine routing, receptor selection has important functional consequences concerning antigen presentation and T-cell stimulation [84]. Consequently, it seems a matter of not only targeting the most suitable DC subtype, but also targeting the most appropriate DC specific receptor to induce a tailormade response [85]. More recently, three receptors unique for the $\mathrm{CDC1}$ subset have been identified, namely, DNGR1 or CLEC9A, CADM1 ${ }^{+}$, and XCR-1. Interestingly, they are all conserved molecules across different species that are also mechanistically involved in the antigen cross-presentation process [86]. Where CLEC9A is involved in the uptake of antigen derived from apoptotic/necrotic cells, CADM1 binds to $\mathrm{CD}^{+} \mathrm{T}$ cells and mediates $\mathrm{DC}: \mathrm{CD}^{+} \mathrm{T}$-cell adhesion, while XCR1 promotes the functional interaction of $\mathrm{CDC1}$ with NK cells and $\mathrm{CD}^{+}{ }^{+} \mathrm{T}$ cells that secrete XCL1 $[87,88]$. Since the cross-presenting $\mathrm{cDC1}$ subset is currently seen as one of the most suitable targets for antitumor immunotherapy, targeting vaccines towards one of these receptors holds great promise for antitumor vaccination $[39,88]$. 
Besides the considerable diversity in APC specific receptors, also in the approach to target these receptors there appears to be plenty of choice.

Based on the overview in Table 2, we can conclude that most studies target their vaccine by coupling it to a short peptide, a ligand, a mAb, or carbohydrate. While the latter has been used extensively to target DCs in situ, they mainly rely on CLR binding, which results in APC but not DC subtype specific binding. On the contrary, the former three moieties could be generated to bind one particular APC subset specific receptor. Other advantages of short peptides are that they do not severely disrupt the original vaccine formation and that targeted peptides with strong binding affinity and unlimited specificity could be generated via highthroughput library approaches $[89,90]$. However, they can hinder multimerisation of monomers, create fusion products with lower thermostability, and hinder proper intracellular trafficking of the vaccine [91]. Alternatively, different kinds of ligands such as cytokines and growth factors have been used $[92,93]$. In addition to peptides and ligands, also mAbs and their derivatives have been evaluated for APC specific targeting. In general, scFvs offer higher specificity than short peptides but as they are larger in size, the chance that they disrupt the process of conformational changes to mediate membrane fusion increases. Therefore, $\mathrm{scFvs}$ are most often linked to a spacer peptide or protease cleavable peptide that permits proper conformation of both the scFv domain and targetable vaccine [94].

Recently described alternatives to the above-mentioned targeting moieties are designed ankyrin repeat proteins (DARPins) and nucleic acid based aptamers as they can be selected to become high-affinity binders to any kind of target molecule $[95,96]$. Another interesting alternative lies in the antigen binding part of heavy-chain-only Abs which are found in members of the family of Camelidae [97, 98]. These antigen-binding parts are only composed of one single variable region, termed $\mathrm{VHH}$ or nanobody. These nanobodies have unique characteristics and offer many advantages over scFvs such as (1) high solubility, (2) ability to refold after denaturation whilst retaining their binding capacity, (3) cloning and selection of antigen specific nanobodies obviating the need for construction and screening large libraries, (4) nonimmunogenic, and (5) being fused to other proteins $[99,100]$. Therefore, it is not surprising that several studies have reported on the generation and subsequent use of nanobodies for APC targeting. Examples hereof are the development of nanobodies targeting CD206 to enabling selective targeting of the MMR ${ }^{\text {hi }} \mathrm{M} 2$ macrophage subset within solid tumors [101]. Furthermore, we also demonstrated that several nanobodies with yet unidentified target antigens allowed targeting of specific human and murine APC subsets, including DCs and macrophages or selective targeting of cDCs [102].

In the case of viral vectors, several additional strategies have been evaluated to alter the broad infection profile of the viral outer membrane embedded glycoproteins towards an APC specific tropism. A first strategy is represented by rational point and domain mutations of the viral glycoprotein. This is exemplified by the DC-SIGN-specific targeting strategy that is based on the fact that the Sindbis virus envelope glycoprotein consists of a fusogenic E1 protein and a cell binding E2 protein. E2 normally binds to the DCSIGN receptor, next to the canonical viral receptor heparin sulphate, expressed by many cell types. Since both protein binding sites are physically separated, selective mutation at the $\mathrm{E} 2$ monomer is possible, abrogating the heparin sulfate binding part while leaving the DC-SIGN binding part intact. By pseudotyping a LV with this mutated Sindbis virus derived envelope glycoprotein, targeted infection of murine DCs after direct subcutaneous administration was achieved. Moreover, this elicited strong and therapeutic antigen specific immune responses [5, 103-105]. Besides genetic alterations, the viral surface can also be chemically engineered to alter the binding specificity. Advantages are the flexibility, speed, and controllable modification conditions [106-108]. Unfortunately, the effectiveness of the chemically modified particles strongly depended on the reaction conditions of the applied modifications $[109,110]$. A final strategy to generate APC targeted LVs is based on the fact that binding and fusion functions of LVs can be separated over two distinct glycoproteins. Recently we exploited this concept to develop DC subtype specific LVs by pseudotyping them with a fusogenic but binding defective glycoprotein on the one hand and an APC specific transmembranary nanobody on the other hand. Briefly we demonstrated $\mathrm{cDC}$ or also $\mathrm{pDC}$ and macrophage specific transduction of human subsets ex vivo and murine subsets in vivo $[4,111]$. Importantly, similar to the report of Ciré et al. [112], who used a MHC-II targeted approach, we showed that intranodal administration of DC targeted LVs enhanced $\mathrm{CD}^{+}{ }^{+} \mathrm{T}$-cell proliferation, without functional nor therapeutic benefit compared to untargeted LVs [45]. Of note, besides viral vectors also bacterial derived vectors or enzymes have been successfully used to target TAAs to DCs with subsequent maturation and induction of strong antitumor immunity [113-115].

In summary an enormous amount of studies have been performed to evidence the added value of DC targeting for antitumor vaccination. However, most receptors (DEC205, DEC206, DC-SIGN, DCIR2, LOX-1, CD11c, CD11b, Fc $\gamma$ receptors, and MHC-II molecules) are not truly specific for one particular APC subset. Subsequently they have been described to internalize antigen by different DC subsets, different APC subsets, and even other non-APCs such as endothelial cells and thymic epithelial cells $[8,116]$, which hampers the evaluation of the DC subtype specific impact on the induced immune response. In addition, several conflicting reports were made in mouse versus human related studies using homologous targeting moieties [117]. For example, when MUC1 was targeted to CD206, a robust CTL response was induced in mice while a robust humoral but only moderate T-cell response was observed in adenocarcinoma patients [106]. In addition, it is difficult to compare the different APC targeting studies since they were performed with very different vaccine moieties with different sizes and surface charge, different doses, diversified formulations, and targeting approaches which can result in completely different pharmacokinetic and immunological outcomes [47]. Therefore, there is an urgent need to define the true meaning of DC 
subset specific targeting to serve our understanding of potent active vaccines for antitumor immunity [118].

\section{Is Targeting a Step Forward in Vaccine Development?}

Although numerous studies evaluated and confirmed the efficacy of DC subtype specific targeting for immunotherapeutic purposes, other studies question its improvement compared to untargeted delivery $[40,45,119]$. Therefore, we want to elaborate in this section on the true meaning of DC (subtype) specific targeting for active antitumor vaccination.

First of all, it has been questioned if it is really possible to target APCs "actively" as they are already specialized in the uptake of whatever antigen they encounter. When Kreutz et al. injected an anti-DEC205 Ab-antigen-adjuvant conjugate in the footpad of mice, preferential uptake by APCs was mediated by the exposed antigen derived peptide and its $\mathrm{CpG}$ nucleic acids rather than by the APC-specific Ab [120]. Also when NPs were decorated with mannosylated alginate or different DC specific targeting Abs, this decoration was less influential on murine DC specific particle uptake, respectively [121, 122]. Furthermore, similar observations were made by our own group with "naked" mRNA where it was shown that after its intranodal delivery mainly CD $8 \alpha^{+}$ DCs were involved in its uptake [52]. This form of "passive" APC targeting was further evidenced by our own observation that noninfectious LVs were able to induce a similar therapeutic benefit in the E.G7-OVA tumor model as the APC targeted LVs after their intranodal delivery [45]. The latter was explained by the uptake of protein contaminants present within the noninfectious LV preparations, which were presumably taken up by the APCs in a nontargeted fashion. Notably, we did demonstrate that our APC targeted LVs outperformed the noninfectious LVs in terms of CD4 ${ }^{+}$ and $\mathrm{CD}^{+}$T-cell stimulation, suggesting that the "active" APC targeting factor does account for better DC activation than "passive" uptake of noninfectious LVs. In contrast, when DC receptor internalization parameters were investigated as well as their impact on antigen presentation outcomes, targeting did turn out to be responsible for antigen presentation after $\mathrm{Ab}$ targeted vaccination in vivo. By analyzing endocytosis of DEC205, CLEC9A, CD11c, CD11b, and CD40 in vitro, they showed that neither the receptor expression level, speed of receptor internalization, and proportion of surface turnover nor the antigen load had an impact on MHC-I or -II mediated antigen presentation. On the contrary, $\mathrm{CD}^{+}$or $\mathrm{CD}^{-}$DC targeting did enhance MHC-II or -I mediated antigen presentation, respectively. Therefore, they concluded that receptor expression levels, speed of internalization, and/or the amount of antigen delivered could be excluded as major determinants of antigen presentation efficiency in the setting of Ab targeted vaccination [123]. One elegant approach is where receptors are upregulated prior to their targeting. This was investigated with a CD206 targeting cancer vaccine composed of mAb fused to an oncofetal protein. They showed that humoral responses to low vaccine doses could be enhanced by prior administration of GM-CSF, which upregulated CD206 expression in human mannose receptor transgenic mice, while coadministration of TLR agonists was required to elicit $\mathrm{T}_{\mathrm{H}} 1$ immunity [124]. However, by prior administration of GM-CSF, one could question if it is the CD206 expression or the overall amount of APCs that is enhanced in situ. From these studies we can conclude that active APC targeting is still debatable and that more studies are warranted to unravel this enigma.

From a practical point of view it has been hypothesized that APC targeted delivery of vaccines could reduce their dose requirement. Hereby one has to distinguish two concepts: (1) APC specific targeting that results in an increased uptake of the vaccine in the case of otherwise "naked" molecules and (2) APC specific targeting to detarget vaccine delivery from all non-APCs in the case of infectious agents such as viral vectors. When APC specific uptake is enhanced, this generally results in a drastically reduced dose requirement $[125,126]$. On the contrary, when we evaluated the CTL inducing capacity of broad tropism versus DC targeted LVs encoding OVA, we could not demonstrate a substantial benefit of DC targeted LVs over broad tropism LVs in terms of dose requirement without loss of efficacy [45]. Another striking observation was made by comparing different doses of in situ delivered targeted versus untargeted infectious nonreplicative OVA-encoding adenoviral vectors. While targeted delivery outperformed untargeted delivery after low dose administration, more effector CD ${ }^{+}$ $\mathrm{T}$ cells were induced with high doses of untargeted vaccine compared to targeted delivery. Interestingly, the protective capacity of the nontargeted vaccine was superior to that of the targeted vaccine in a tumor challenge model, demonstrating dose-dependent effects of DC targeting on the quality of the induced immune response [127].

In terms of safety, vaccine detargeting from nonimmunogenic stromal cells could reduce the risk of adverse reactions such as the development of autoimmunity and the induction of tolerance or unwanted systemic cytokine release due to overstimulation $[119,128,129]$. Indeed, targeted delivery of TLR agonists reduced their dose requirement by 100 -fold and was associated with a decreased serum cytokine storm and related toxicities in vivo, compared to administration of soluble adjuvants [130]. Furthermore, APC targeting potentially reduces the risk for insertional mutagenesis when DNA and LV-based vaccines are directly administered since APCs are differentiated short-living cells which are unlikely to transform into malignant cells.

Next, APC subtype specific targeting is believed to allow the induction of a very specific fine-tuned immune response. Since the disentanglement of the heterogeneity of different APC subtypes, their specific targeting paved the way towards fundamental research on the exact therapeutic role of each APC subset in antitumor immunotherapy. Moreover, DC subtype specific targeting has already been reported for CLEC9A/BDCA-3 (murine/human cDC1), DCIR-2 (murine cDC2), BDCA-2 (human pDCs), SiglecH and BST2 (murine pDCs), and langerin (LCs) and showed promising differences in the elicited immune responses as a reflection of the specific function of these DC subtypes in situ [11, 81, 131-135]. However, DC subset specific functions are not fixed but vary 
among several factors such as species and inflammatory state. This is exemplified by the presumed most favorable target for antitumor vaccination: the most professionalized crosspresenting XCR1/CLEC9A ${ }^{+} \mathrm{CDC1}$ subset [88]. While they are peculiarly equipped to cross-present antigens from dead cells, they seem equally potent to cross-present soluble antigens when compared to other DC subtypes [136]. Of note, in mice the $\mathrm{CDC1}$ subset represents the main IL-12 producing population, while, in humans, IL-12 production is not limited to the $\mathrm{CD}_{141^{+}}$subset. Importantly, the lymphoid tissue $\mathrm{CD} 8 \alpha^{+}$ and nonlymphoid tissue $\mathrm{CD}_{103}{ }^{+} \mathrm{DCs}$ are also mediators of systemic and intestinal tolerance, respectively. Thus, the cDC1 lineage responds to its local microenvironment in order to induce either tolerance or cross-presentation dependent $\mathrm{CD}^{+} \mathrm{T}$-cell immunity. In line with these observations, the human $\mathrm{BDCA}^{+} \mathrm{DC}$ equivalents of the murine $\mathrm{DC} 8 \alpha^{+} \mathrm{cDCs}$ have also been shown to excellently cross-present antigens on the one hand but to suppress an immune response on the other hand by secreting IL-10 and inducing Tregs [137]. Nevertheless, when CLEC9A and XCR1, specific for CDC1, were targeted, this approach appeared potent to eradicate established melanomas $[88,138]$. Interestingly, however, it was also shown that when CLEC9A was coupled to polyI:C, curdlan or nothing, the vaccine was able to modulate $\mathrm{CD} 4^{+}$ $\mathrm{T}$ cells into $\mathrm{T}_{\mathrm{H}} 1, \mathrm{~T}_{\mathrm{H}} 17$ or Tregs, respectively [139], suggesting that the embedded adjuvant in the vaccine is more decisive for the immunological outcome than the cell type specific receptor towards which it is targeted.

Finally, targeting is believed to enhance the vaccine's immune stimulatory potential since detargeting TAAs from non-APCs but also B cells and macrophages could avoid the induction of tolerance or rapid antigen degradation. Indeed, when mice were treated with OVA, coupled or fused to Abs against DEC205, a more than 100-fold efficient and potent response was measured compared to untargeted antigens $[128,131]$. Furthermore, several preclinical and clinical trials have demonstrated the effectiveness of APC targeted vaccines for human immunotherapy, which are summarized elsewhere [140]. However, most studies evaluating targeted antitumor vaccination are based on targeting receptors such as DEC205 and the mannose receptor CD206 (see Table 2), which are not specifically expressed by one particular DC subset. Therefore, it is hard to draw any conclusions with regard to an enhanced efficiency for antitumor immunity upon exclusive targeting of one DC subset. Moreover, when we targeted cDCs alone or also pDCs and macrophages using nanobody displaying LVs encoding OVA, we only observed clear differences in the induced $\mathrm{CD}_{4}^{+} \mathrm{T}$-cell profiles, while the therapeutic outcome of the $\mathrm{CDC}$ and the $\mathrm{CDC}$ as well as pDC targeted vaccine was comparable but most importantly less strong than that of the broad tropism LV vaccine [45]. Furthermore, it has been questioned if targeting as such is responsible for the increased immunogenicity compared to untargeted delivery, since this increase has also been ascribed to the immunomodulating role of the targeting moiety itself and less by targeting the specific DC subset [120, 121, 141].

So, based on our current knowledge, there is no strong rationale to target one DC subset over another to prime TAA specific CTLs and additional in vivo studies with human DC subset specific targets are definitely needed to identify the most specialized DC subsets, if any [142], a rationale that is further signified by reports on bystander maturation of cDCs by pDCs as well as on the need for multiple DC subset activation for optimal $\mathrm{T}_{\mathrm{H}} 1$ and effector T-cell immunity [6, $14,143]$. This is exemplified by a study where the combination of BDCA3 and DC-SIGN targeted NPs was superior to targeting either subset alone in terms of T-cell activation. The mechanism underlying the observed synergy involved IL-15dependent DC-DC cross talk suggesting that targeting only one APC subset could deprive the resultant immune response from the benefit of cross talk between different DC subsets [144]. Therefore, upcoming treatment paradigms should aim to include several primary DC subsets in a single vaccine as preclinical studies identified synergistic effects between various APCs [145].

\section{Conclusions}

An overload of targeted vaccination studies demonstrate that vaccination can be tailor-made to induce a particular phenotype of adaptive immunity by specifically targeting different surface molecules on DC subsets [146]. Nonetheless, conflicting results regarding the outcome of targeted vaccines to induce therapeutic antitumor immunity also stress that the benefit of targeting as such may not be overestimated. The immunogenicity of every vaccine, irrespective of its targeting abilities, is also characterized by its dose, size, surface charge, cargo, presence of adjuvants, route of administration, and the species to which it is delivered. So the question remains: does one targetable and omnipotent DC subtype really exists to increase the efficiency of current antitumor vaccination strategies?

\section{Conflict of Interests}

The authors declare that there is no conflict of interests regarding the publication of this review.

\section{References}

[1] K. Breckpot, C. Heirman, B. Neyns, and K. Thielemans, "Exploiting dendritic cells for cancer immunotherapy: genetic modification of dendritic cells," Journal of Gene Medicine, vol. 6, no. 11, pp. 1175-1188, 2004.

[2] K. F. Bol, J. Tel, I. J. M. de Vries, and C. G. Figdor, "Naturally circulating dendritic cells to vaccinate cancer patients," OncoImmunology, vol. 2, no. 3, Article ID e23431, 2013.

[3] K. Shortman, M. H. Lahoud, and I. Caminschi, "Improving vaccines by targeting antigens to dendritic cells," Experimental and Molecular Medicine, vol. 41, no. 2, pp. 61-66, 2009.

[4] C. Goyvaerts, K. De Groeve, J. Dingemans et al., "Development of the Nanobody display technology to target lentiviral vectors to antigen-presenting cells," Gene Therapy, vol. 19, no. 12, pp. 1133-1140, 2012.

[5] L. Yang, H. Yang, K. Rideout et al., "Engineered lentivector targeting of dendritic cells for in vivo immunization," Nature Biotechnology, vol. 26, no. 3, pp. 326-334, 2008. 
[6] K. Sehgal, K. M. Dhodapkar, and M. V. Dhodapkar, “Targeting human dendritic cells in situ to improve vaccines," Immunology Letters, vol. 162, no. 1, pp. 59-67, 2014.

[7] F. Arce, K. Breckpot, M. Collins, and D. Escors, "Targeting lentiviral vectors for cancer immunotherapy," Current Cancer Therapy Reviews, vol. 7, no. 4, pp. 248-260, 2011.

[8] V. Apostolopoulos, T. Thalhammer, A. G. Tzakos, and L. Stojanovska, "Targeting antigens to dendritic cell receptors for vaccine development," Journal of Drug Delivery, vol. 2013, Article ID 869718, 22 pages, 2013.

[9] N. Bhardwaj, J. W. Young, A. J. Nisanian, J. Baggers, and R. M. Steinman, "Small amounts of superantigen, when presented on dendritic cells, are sufficient to initiate T cell responses," The Journal of Experimental Medicine, vol. 178, no. 2, pp. 633-642, 1993.

[10] R. M. Steinman and Z. A. Cohn, "Identification of a novel cell type in peripheral lymphoid organs of mice. I. Morphology, quantitation, tissue distribution," The Journal of Experimental Medicine, vol. 137, no. 5, pp. 1142-1162, 1973.

[11] D. Dudziak, A. O. Kamphorst, G. F. Heidkamp et al., "Differential antigen processing by dendritic cell subsets in vivo," Science, vol. 315, no. 5808, pp. 107-111, 2007.

[12] R. S. Allan, J. Waithman, S. Bedoui et al., "Migratory dendritic cells transfer antigen to a lymph node-resident dendritic cell population for efficient CTL priming," Immunity, vol. 25, no. 1, pp. 153-162, 2006.

[13] L. M. Wakim and M. J. Bevan, "Cross-dressed dendritic cells drive memory $\mathrm{CD}^{+}$T-cell activation after viral infection," Nature, vol. 471, no. 7340, pp. 629-632, 2011.

[14] C. Coquerelle and M. Moser, "DC subsets in positive and negative regulation of immunity," Immunological Reviews, vol. 234, no. 1, pp. 317-334, 2010.

[15] K. Breckpot, A. Bonehill, and J. L. Aerts, Dendritic Cells: Subtypes, Life Cycle, Activation, Biological Functions and their Exploitation in Cancer Immunotherapy, 2010.

[16] A. Mildner and S. Jung, "Development and function of dendritic cell subsets," Immunity, vol. 40, no. 5, pp. 642-656, 2014.

[17] A. K. Palucka, H. Ueno, J. Fay, and J. Banchereau, "Dendritic cells: a critical player in cancer therapy?" Journal of Immunotherapy, vol. 31, no. 9, pp. 793-805, 2008.

[18] D. Hawiger, K. Inaba, Y. Dorsett et al., "Dendritic cells induce peripheral $\mathrm{T}$ cell unresponsiveness under steady state conditions in vivo," Journal of Experimental Medicine, vol. 194, no. 6, pp. 769-779, 2001.

[19] D. K. Banerjee, M. V. Dhodapkar, E. Matayeva, R. M. Steinman, and K. M. Dhodapkar, "Expansion of FOXP3high regulatory T cells by human dendritic cells (DCs) in vitro and after injection of cytokine-matured DCs in myeloma patients," Blood, vol. 108, no. 8, pp. 2655-2661, 2006.

[20] A. L. Blasius and B. Beutler, "Intracellular toll-like receptors," Immunity, vol. 32, no. 3, pp. 305-315, 2010.

[21] T. Kawai and S. Akira, "Toll-like receptor and RIG-1-like receptor signaling," Annals of the New York Academy of Sciences, vol. 1143, pp. 1-20, 2008.

[22] G. M. Barton and J. C. Kagan, "A cell biological view of Toll-like receptor function: regulation through compartmentalization," Nature Reviews Immunology, vol. 9, no. 8, pp. 535-542, 2009.

[23] T. B. H. Geijtenbeek and S. I. Gringhuis, "Signalling through C-type lectin receptors: shaping immune responses," Nature Reviews Immunology, vol. 9, no. 7, pp. 465-479, 2009.
[24] K. Breckpot and D. Escors, "Dendritic cells for active anticancer immunotherapy: targeting activation pathways through genetic modification," Endocrine, Metabolic and Immune Disorders-Drug Targets, vol. 9, no. 4, pp. 328-343, 2009.

[25] N. Onai, A. Obata-Onai, M. A. Schmid, T. Ohteki, D. Jarrossay, and M. G. Manz, "Identification of clonogenic common $\mathrm{Flt}^{+} \mathrm{M}^{-\mathrm{CSFR}^{+}}$plasmacytoid and conventional dendritic cell progenitors in mouse bone marrow," Nature Immunology, vol. 8, no. 11, pp. 1207-1216, 2007.

[26] M. Guilliams, F. Ginhoux, C. Jakubzick et al., "Dendritic cells, monocytes and macrophages: a unified nomenclature based on ontogeny," Nature Reviews Immunology, vol. 14, no. 8, pp. 571578, 2014.

[27] H. S. Ghosh, B. Cisse, A. Bunin, K. L. Lewis, and B. Reizis, "Continuous expression of the transcription factor e2-2 maintains the cell fate of mature plasmacytoid dendritic cells," Immunity, vol. 33, no. 6, pp. 905-916, 2010.

[28] A. Schlitzer and F. Ginhoux, "Organization of the mouse and human DC network," Current Opinion in Immunology, vol. 26, pp. 90-99, 2014.

[29] C.-A. Dutertre, L.-F. Wang, and F. Ginhoux, "Aligning bona fide dendritic cell populations across species," Cellular Immunology, vol. 291, no. 1-2, pp. 3-10, 2014.

[30] G. T. Belz and S. L. Nutt, "Transcriptional programming of the dendritic cell network," Nature Reviews Immunology, vol. 12, no. 2, pp. 101-113, 2012.

[31] L. Chorro, A. Sarde, M. Li et al., "Langerhans cell (LC) proliferation mediates neonatal development, homeostasis, and inflammation-associated expansion of the epidermal LC network," The Journal of Experimental Medicine, vol. 206, no. 13, pp. 3089-3100, 2009.

[32] F. P. Siegal, N. Kadowaki, M. Shodell et al., "The nature of the principal type 1 interferon-producing cells in human blood," Science, vol. 284, no. 5421, pp. 1835-1837, 1999.

[33] C. Cheong, I. Matos, J.-H. Choi et al., "Microbial stimulation fully differentiates monocytes to DC-SIGN/CD209 ${ }^{+}$dendritic cells for immune T cell areas," Cell, vol. 143, no. 3, pp. 416-429, 2010.

[34] E. Klechevsky and J. Banchereau, "Human dendritic cells subsets as targets and vectors for therapy," Annals of the New York Academy of Sciences, vol. 1284, no. 1, pp. 24-30, 2013.

[35] M. Haniffa, A. Shin, V. Bigley et al., "Human tissues contain CD $141^{\text {hi }}$ cross-presenting dendritic cells with functional homology to mouse $\mathrm{CD}_{103^{+}}$nonlymphoid dendritic cells," Immunity, vol. 37, no. 1, pp. 60-73, 2012.

[36] K. Shortman and W. R. Heath, "The CD8 ${ }^{+}$dendritic cell subset," Immunological Reviews, vol. 234, no. 1, pp. 18-31, 2010.

[37] M. Semmrich, M. Plantinga, M. Svensson-Frej et al., "Directed antigen targeting in vivo identifies a role for $\mathrm{CD}_{103}{ }^{+}$dendritic cells in both tolerogenic and immunogenic T-cell responses," Mucosal Immunology, vol. 5, no. 2, pp. 150-160, 2012.

[38] S. Meixlsperger, C. S. Leung, P. C. Rämer et al., "CD141+ dendritic cells produce prominent amounts of IFN- $\alpha$ after dsRNA recognition and can be targeted via DEC-205 in humanized mice," Blood, vol. 121, no. 25, pp. 5034-5044, 2013.

[39] M. L. Broz, M. Binnewies, B. Boldajipour et al., "Dissecting the tumor myeloid compartment reveals rare activating antigenpresenting cells critical for T cell immunity," Cancer Cell, vol. 26, no. 5, pp. 638-652, 2014.

[40] W. Kastenmüller, K. Kastenmüller, C. Kurts, and R. A. Seder, "Dendritic cell-targeted vaccines-hope or hype?" Nature Reviews Immunology, vol. 14, no. 10, pp. 705-711, 2014. 
[41] K. Palucka, J. Banchereau, and I. Mellman, "Designing vaccines based on biology of human dendritic cell subsets," Immunity, vol. 33, no. 4, pp. 464-478, 2010.

[42] H. Hochrein, M. O'Keeffe, and H. Wagner, "Human and mouse plasmacytoid dendritic cells," Human Immunology, vol. 63, no. 12, pp. 1103-1110, 2002.

[43] J. Tel, E. H. J. G. Aarntzen, T. Baba, and et al, "Natural human plasmacytoid dendritic cells induce antigen-specific Tcell responses in melanoma patients," Cancer Research, vol. 73, no. 3, pp. 1063-1075, 2013.

[44] K. Palucka, H. Ueno, L. Roberts, J. Fay, and J. Banchereau, "Dendritic cell subsets as vectors and targets for improved cancer therapy," Current Topics In Microbiology and Immunology, vol. 344, pp. 173-192, 2011.

[45] C. Goyvaerts, D. G. Kurt, S. Van Lint et al., "Immunogenicity of targeted lentivectors," Oncotarget, vol. 5, no. 3, pp. 704-715, 2014.

[46] S. Van Lint, D. Renmans, K. Broos et al., "The ReNAissanCe of mRNA-based cancer therapy," Expert Review of Vaccines, vol. 14, no. 2, pp. 235-251, 2015.

[47] Z. Amoozgar and M. S. Goldberg, "Targeting myeloid cells using nanoparticles to improve cancer immunotherapy," Advanced Drug Delivery Reviews, 2014.

[48] H. Dewitte, R. Verbeke, K. Breckpot, S. C. De Smedt, and I. Lentacker, "Nanoparticle design to induce tumor immunity and challenge the suppressive tumor microenvironment," Nano Today, vol. 9, no. 6, pp. 743-758, 2014.

[49] M. Dullaers, S. Van Meirvenne, C. Heirman et al., "Induction of effective therapeutic antitumor immunity by direct in vivo administration of lentiviral vectors," Gene Therapy, vol. 13, no. 7, pp. 630-640, 2006.

[50] L. Chapatte, S. Colombetti, J.-C. Cerottini, and F. Lévy, "Efficient induction of tumor antigen-specific $\mathrm{CD}^{+}$memory $\mathrm{T}$ cells by recombinant lentivectors," Cancer Research, vol. 66, no. 2, pp. 1155-1160, 2006.

[51] S. Rusakiewicz, M. Dosset, K. Mollier et al., "Immunogenicity of a recombinant lentiviral vector carrying human telomerase tumor antigen in HLA-B ${ }^{*} 0702$ transgenic mice," Vaccine, vol. 28, no. 38, pp. 6374-6381, 2010.

[52] S. Van Lint, C. Goyvaerts, S. Maenhout et al., "Preclinical evaluation of TriMix and antigen mRNA-based antitumor therapy," Cancer Research, vol. 72, no. 7, pp. 1661-1671, 2012.

[53] I. C. Kourtis, S. Hirosue, A. de Titta et al., "Peripherally administered nanoparticles target monocytic myeloid cells, secondary lymphoid organs and tumors in mice," PLoS ONE, vol. 8, no. 4, Article ID e61646, 2013.

[54] C. Wang, P. Liu, Y. Zhuang et al., "Lymphatic-targeted cationic liposomes: a robust vaccine adjuvant for promoting long-term immunological memory," Vaccine, vol. 32, no. 42, pp. 54755483, 2014.

[55] N. K. Kunda, I. M. Alfagih, S. R. Dennison et al., "Bovine serum albumin adsorbed PGA-co-PDL nanocarriers for vaccine delivery via dry powder inhalation," Pharmaceutical Research, vol. 32, no. 4, pp. 1341-1353, 2015.

[56] S. N. Thomas, E. Vokali, A. W. Lund, J. A. Hubbell, and M. A. Swartz, "Targeting the tumor-draining lymph node with adjuvanted nanoparticles reshapes the anti-tumor immune response," Biomaterials, vol. 35, no. 2, pp. 814-824, 2014.

[57] L. Jeanbart, M. Ballester, A. de Titta et al., "Enhancing efficacy of anticancer vaccines by targeted delivery to tumor-draining lymph nodes," Cancer Immunology Research, vol. 2, no. 5, pp. 436-447, 2014.
[58] H. Dewitte, S. Van Lint, C. Heirman et al., "The potential of antigen and TriMix sonoporation using mRNA-loaded microbubbles for ultrasound-triggered cancer immunotherapy," Journal of Controlled Release, vol. 194, pp. 28-36, 2014.

[59] M. Zaric, O. Lyubomska, C. Poux et al., "Dissolving microneedle delivery of nanoparticle-encapsulated antigen elicits efficient cross-priming and Th1 immune responses by murine langerhans cells," Journal of Investigative Dermatology, vol. 135, no. 2, pp. 425-434, 2014.

[60] M. Zaric, O. Lyubomska, O. Touzelet et al., "Skin dendritic cell targeting via microneedle arrays laden with antigenencapsulated poly-D,L-lactide-co-glycolide nanoparticles induces efficient antitumor and antiviral immune responses," ACS Nano, vol. 7, no. 3, pp. 2042-2055, 2013.

[61] K. Van der Jeught, L. Bialkowski, L. Daszkiewicz et al., "Targeting the tumor microenvironment to enhance antitumor immune responses," Oncotarget, vol. 6, no. 3, pp. 1359-1381, 2015.

[62] S. A. Rosenberg, R. M. Sherry, K. E. Morton et al., "Tumor progression can occur despite the induction of very high levels of self/tumor antigen-specific $\mathrm{CD}^{+} \mathrm{T}$ cells in patients with melanoma," The Journal of Immunology, vol. 175, no. 9, pp. 61696176, 2005.

[63] A. A. Keskinov and M. R. Shurin, "Myeloid regulatory cells in tumor spreading and metastasis," Immunobiology, vol. 220, pp. 236-242, 2014.

[64] J. M. T. Janco, P. Lamichhane, L. Karyampudi, and K. L. Knutson, "Tumor-infiltrating dendritic cells in cancer pathogenesis," The Journal of Immunology, vol. 194, no. 7, pp. 2985-2991, 2015.

[65] S. Kim, G. J. Kim, H. Miyoshi et al., "Efficiency of the elongation factor-1alpha promoter in mammalian embryonic stem cells using lentiviral gene delivery systems," Stem Cells and Development, vol. 16, no. 4, pp. 537-545, 2007.

[66] D. E. Gilham, M. Lie-A-Ling, N. Taylor, and R. E. Hawkins, "Cytokine stimulation and the choice of promoter are critical factors for the efficient transduction of mouse T cells with HIV-1 vectors," The Journal of Gene Medicine, vol. 12, no. 2, pp. 129-136, 2010.

[67] M. Li, N. Husic, Y. Lin et al., "Optimal promoter usage for lentiviral vector-mediated transduction of cultured central nervous system cells," Journal of Neuroscience Methods, vol. 189, no. 1, pp. 56-64, 2010.

[68] B. H. Liu, X. Wang, Y. X. Ma, and S. Wang, "CMV enhancer/human PDGF- $\beta$ promoter for neuron-specific transgene expression," Gene Therapy, vol. 11, no. 1, pp. 52-60, 2004.

[69] S. Stein, M. G. Ott, S. Schultze-Strasser et al., "Genomic instability and myelodysplasia with monosomy 7 consequent to EVI1 activation after gene therapy for chronic granulomatous disease," Nature Medicine, vol. 16, no. 2, pp. 198-204, 2010.

[70] F. Di Nunzio, G. Maruggi, S. Ferrari et al., "Correction of laminin-5 deficiency in human epidermal stem cells by transcriptionally targeted lentiviral vectors," Molecular Therapy, vol. 16, no. 12, pp. 1977-1985, 2008.

[71] J. Cao, K. Sodhi, K. Inoue et al., "Lentiviral-human heme oxygenase targeting endothelium improved vascular function in angiotensin II animal model of hypertension," Human Gene Therapy, vol. 22, no. 3, pp. 271-282, 2011.

[72] L. Lopes, M. Dewannieux, U. Gileadi et al., "Immunization with a lentivector that targets tumor antigen expression to dendritic cells induces potent $\mathrm{CD} 8^{+}$and $\mathrm{CD} 4^{+} \mathrm{T}$-cell responses," Journal of Virology, vol. 82, no. 1, pp. 86-95, 2008.

[73] Y. Cui, J. Golob, E. Kelleher, Z. Ye, D. Pardoll, and L. Cheng, "Targeting transgene expression to antigen-presenting cells 
derived from lentivirus-transduced engrafting human hematopoietic stem/progenitor cells," Blood, vol. 99, no. 2, pp. 399-408, 2002.

[74] M. Pincha, G. Salguero, D. Wedekind et al., "Lentiviral vectors for induction of self-differentiation and conditional ablation of dendritic cells," Gene Therapy, vol. 18, no. 8, pp. 750-764, 2011.

[75] V. Moulin, M. E. Morgan, D. Eleveld-Trancikova et al., "Targeting dendritic cells with antigen via dendritic cell-associated promoters," Cancer Gene Therapy, vol. 19, no. 5, pp. 303-311, 2012.

[76] C. Dresch, S. L. Edelmann, P. Marconi, and T. Brocker, "Lentiviral-mediated transcriptional targeting of dendritic cells for induction of T cell tolerance in vivo," Journal of Immunology, vol. 181, no. 7, pp. 4495-4506, 2008.

[77] B. De Andrade Pereira, C. Fraefel, M. Hilbe, M. Ackermann, and C. Dresch, "Transcriptional targeting of DCs with lentiviral vectors induces antigen-specific tolerance in a mouse model of multiple sclerosis," Gene Therapy, vol. 20, no. 5, pp. 556-566, 2013.

[78] M. De Palma, E. Montini, F. R. Santoni De Sio et al., "Promoter trapping reveals significant differences in integration site selection between MLV and HIV vectors in primary hematopoietic cells," Blood, vol. 105, no. 6, pp. 2307-2315, 2005.

[79] A. Schambach, D. Zychlinski, B. Ehrnstroem, and C. Baum, "Biosafety features of lentiviral vectors," Human Gene Therapy, vol. 24, no. 2, pp. 132-142, 2013.

[80] B. Barrilleaux and P. Knoepfler, "Transduction of human cells with polymer-complexed ecotropic lentivirus for enhanced biosafety," Journal of Visualized Experiments, no. 53, 2011.

[81] C. G. Park, "Vaccine strategies utilizing C-type lectin receptors on dendritic cells in vivo," Clinical and Experimental Vaccine Research, vol. 3, no. 2, pp. 149-154, 2014.

[82] I. Streng-Ouwehand, W. W. J. Unger, and Y. Van Kooyk, "Ctype lectin receptors for tumor eradication: future directions," Cancers, vol. 3, no. 3, pp. 3169-3188, 2011.

[83] C. L. Van Broekhoven, C. R. Parish, C. Demangel, W. J. Britton, and J. G. Altin, "Targeting dendritic cells with antigencontaining liposomes: a highly effective procedure for induction of antitumor immunity and for tumor immunotherapy," Cancer Research, vol. 64, no. 12, pp. 4357-4365, 2004.

[84] Y. Liu, A. Tai, K.-I. Joo, and P. Wang, "Visualization of DCSIGN-mediated entry pathway of engineered lentiviral vectors in target cells," PLoS ONE, vol. 8, no. 6, Article ID e67400, 2013.

[85] D. Li, G. Romain, A.-L. Flamar et al., "Targeting self- and foreign antigens to dendritic cells via DC-ASGPR generates IL-10producing suppressive $\mathrm{CD}^{+}{ }^{+} \mathrm{T}$ cells," Journal of Experimental Medicine, vol. 209, no. 1, pp. 109-121, 2012.

[86] A. Bachem, E. Hartung, S. Güttler et al., "Expression of XCR1 characterizes the Batf3-dependent lineage of dendritic cells capable of antigen cross-presentation," Frontiers in Immunology, vol. 3, article 214, 2012.

[87] A. Bachem, S. Güttler, E. Hartung et al., "Superior antigen cross-presentation and XCR1 expression define human

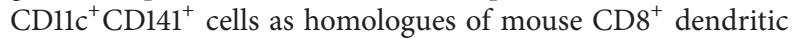
cells," Journal of Experimental Medicine, vol. 207, no. 6, pp. 12731281, 2010.

[88] K. M. Tullett, M. H. Lahoud, and K. J. Radford, "Harnessing human cross-presenting CLEC9 $\mathrm{A}^{+} \mathrm{XCR}^{+}$dendritic cells for immunotherapy," Frontiers in Immunology, vol. 5, article 239, 2014.
[89] D. V. Schaffer, J. T. Koerber, and K. Lim, "Molecular engineering of viral gene delivery vehicles," Annual Review of Biomedical Engineering, vol. 10, no. 1, pp. 169-194, 2008.

[90] M. Sioud, G. Skorstad, A. Mobergslien, and S. Sæbøe-Larssen, "A novel peptide carrier for efficient targeting of antigens and nucleic acids to dendritic cells," The FASEB Journal, vol. 27, no. 8, pp. 3272-3283, 2013.

[91] G. H. Guibinga, F. L. Hall, E. M. Gordon, E. Ruoslahti, and T. Friedmann, "Ligand-modified vesicular stomatitis virus glycoprotein displays a temperature-sensitive intracellular trafficking and virus assembly phenotype," Molecular Therapy, vol. 9, no. 1, pp. 76-84, 2004.

[92] D. Lavillette, S. J. Russell, and F.-L. Cosset, "Retargeting gene delivery using surface-engineered retroviral vector particles," Current Opinion in Biotechnology, vol. 12, no. 5, pp. 461-466, 2001.

[93] M. Katane, E. Takao, Y. Kubo, R. Fujita, and H. Amanuma, "Factors affecting the direct targeting of murine leukemia virus vectors containing peptide ligands in the envelope protein," EMBO Reports, vol. 3, no. 9, pp. 899-904, 2002.

[94] G. Karavanas, M. Marin, E. Bachrach, A. G. Papavassiliou, and M. Piechaczyk, "The insertion of an anti-MHC I ScFv into the $\mathrm{N}$-terminus of an ecotropic MLV glycoprotein does not alter its fusiogenic potential on murine cells," Virus Research, vol. 83, no. 1-2, pp. 57-69, 2002.

[95] B. C. Wengerter, J. A. Katakowski, J. M. Rosenberg et al., "Aptamer-targeted antigen delivery," Molecular Therapy, vol. 22, no. 7, pp. 1375-1387, 2014.

[96] R. C. Münch, M. D. Mühlebach, T. Schaser et al., "DARPins: an efficient targeting domain for lentiviral vectors," Molecular Therapy, vol. 19, no. 4, pp. 686-693, 2011.

[97] C. Hamers-Casterman, T. Atarhouch, S. Muyldermans et al., "Naturally occurring antibodies devoid of light chains," Nature, vol. 363, no. 6428, pp. 446-448, 1993.

[98] S. Muyldermans, "Nanobodies: natural single-domain antibodies," Annual Review of Biochemistry, vol. 82, no. 1, pp. 775-797, 2013.

[99] I. Vaneycken, M. D’huyvetter, S. Hernot et al., "Immunoimaging using nanobodies," Current Opinion in Biotechnology, vol. 22, no. 6, pp. 877-881, 2011.

[100] J. De Vos, N. Devoogdt, T. Lahoutte, and S. Muyldermans, "Camelid single-domain antibody-fragment engineering for (pre)clinical in vivo molecular imaging applications: adjusting the bullet to its target," Expert Opinion on Biological Therapy, vol. 13, no. 8, pp. 1149-1160, 2013.

[101] K. Movahedi, S. Schoonooghe, D. Laoui et al., "Nanobodybased targeting of the macrophage mannose receptor for effective in vivo imaging of tumor-associated macrophages," Cancer Research, vol. 72, no. 16, pp. 4165-4177, 2012.

[102] K. De Groeve, N. Deschacht, C. De Koninck et al., "Nanobodies as tools for in vivo imaging of specific immune cell types," Journal of Nuclear Medicine, vol. 51, no. 5, pp. 782-789, 2010.

[103] L. Xiao, K.-I. Joo, M. Lim, and P. Wang, "Dendritic cell-directed vaccination with a lentivector encoding PSCA for prostate cancer in mice," PloS ONE, vol. 7, no. 11, Article ID e48866, 2012.

[104] B. Hu, B. Dai, and P. Wang, "Vaccines delivered by integrationdeficient lentiviral vectors targeting dendritic cells induces strong antigen-specific immunity," Vaccine, vol. 28, no. 41, pp. 6675-6683, 2010.

[105] B. Dai, L. Yang, H. Yang, B. Hu, D. Baltimore, and P. Wang, "HIV-1 Gag-specific immunity induced by a lentivector-based 
vaccine directed to dendritic cells," Proceedings of the National Academy of Sciences of the United States of America, vol. 106, no. 48, pp. 20382-20387, 2009.

[106] V. Karanikas, L.-A. Hwang, J. Pearson et al., "Antibody and $T$ cell responses of patients with adenocarcinoma immunized with mannan-MUC1 fusion protein," The Journal of Clinical Investigation, vol. 100, no. 11, pp. 2783-2792, 1997.

[107] M. A. Croyle, S. M. Callahan, A. Auricchio et al., "PEGylation of a vesicular stomatitis virus $G$ pseudotyped lentivirus vector prevents inactivation in serum," Journal of Virology, vol. 78, no. 2, pp. 912-921, 2004.

[108] J.-C. Zeng, Z. Zhang, T.-Y. Li et al., "Assessing the role of IL-35 in colorectal cancer progression and prognosis," International Journal of Clinical and Experimental Pathology, vol. 6, no. 9, pp. 1806-1816, 2013.

[109] C. J. Buchholz, L. J. Duerner, S. Funke, and I. C. Schneider, "Retroviral display and high throughput screening," Combinatorial Chemistry and High Throughput Screening, vol. 11, no. 2, pp. 99-110, 2008.

[110] C. Metzner, F. Kochan, and J. A. Dangerfield, "Postexit surface engineering of retroviral/lentiviral vectors," BioMed Research International, vol. 2013, Article ID 253521, 8 pages, 2013.

[111] C. Goyvaerts, J. Dingemans, K. De Groeve et al., "Targeting of human antigen-presenting cell subsets," Journal of Virology, vol. 87, no. 20, pp. 11304-11308, 2013.

[112] S. Ciré, S. Da Rocha, R. Yao et al., "Immunization of mice with lentiviral vectors targeted to MHC class II+ cells is due to preferential transduction of dendritic cells in vivo," PLoS ONE, vol. 9, no. 7, Article ID e101644, 2014.

[113] G. Dadaglio, C. Fayolle, X. Zhang et al., "Antigen targeting to $\mathrm{CD}_{11 \mathrm{~b}}{ }^{+}$dendritic cells in association with TLR4/TRIF signaling promotes strong $\mathrm{CD}^{+} \mathrm{T}$ cell responses," Journal of Immunology, vol. 193, no. 4, pp. 1787-1798, 2014.

[114] M. M. Seavey, Z.-K. Pan, P. C. Maciag et al., "A novel human Her-2/neu chimeric molecule expressed by listeria monocytogenes can elicit potent HLA-A2 restricted CD8-positive T cell responses and impact the growth and spread of Her-2/neupositive breast tumors," Clinical Cancer Research, vol. 15, no. 3, pp. 924-932, 2009.

[115] D. T. Le, T. W. Dubenksy Jr., and D. G. Brockstedt, "Clinical development of listeria monocytogenes-based immunotherapies," Seminars in Oncology, vol. 39, no. 3, pp. 311-322, 2012.

[116] C. S. Leung, M. A. Maurer, S. Meixlsperger et al., "Robust Tcell stimulation by Epstein-Barr virus-transformed B cells after antigen targeting to DEC-205," Blood, vol. 121, no. 9, pp. 15841594, 2013.

[117] M. D. Joshi, W. J. Unger, G. Storm, Y. Van Kooyk, and E. Mastrobattista, "Targeting tumor antigens to dendritic cells using particulate carriers," Journal of Controlled Release, vol. 161, no. 1, pp. 25-37, 2012.

[118] M. Maglinao, M. Eriksson, M. K. Schlegel et al., "A platform to screen for C-type lectin receptor-binding carbohydrates and their potential for cell-specific targeting and immune modulation," Journal of Controlled Release, vol. 175, no. 1, pp. 36-42, 2014.

[119] M. Kreutz, P. J. Tacken, and C. G. Figdor, "Targeting dendritic cells-why bother?” Blood, vol. 121, no. 15, pp. 2836-2844, 2013.

[120] M. Kreutz, B. Giquel, Q. Hu et al., "Antibody-antigen-adjuvant conjugates enable co-delivery of antigen and adjuvant to dendritic cells in cis but only have partial targeting specificity," PLoS ONE, vol. 7, no. 7, Article ID e40208, 2012.
[121] L. J. Thomann-Harwood, P. Kaeuper, N. Rossi, P. Milona, B. Herrmann, and K. C. McCullough, "Nanogel vaccines targeting dendritic cells: contributions of the surface decoration and vaccine cargo on cell targeting and activation," Journal of Controlled Release, vol. 166, no. 2, pp. 95-105, 2013.

[122] L. E. Ruff, E. A. Mahmoud, J. Sankaranarayanan et al., "Antigenloaded $\mathrm{pH}$-sensitive hydrogel microparticles are taken up by dendritic cells with no requirement for targeting antibodies," Integrative Biology, vol. 5, no. 1, pp. 195-203, 2013.

[123] A. Reuter, S. E. Panozza, C. Macri et al., "Criteria for dendritic cell receptor selection for efficient antibody-targeted vaccination," The Journal of Immunology, vol. 194, no. 6, pp. 2696-2705, 2015.

[124] L.-Z. He, J. Weidlick, C. Sisson, H. C. Marsh, and T. Keler, "Toll-like receptor agonists shape the immune responses to a mannose receptor-targeted cancer vaccine," Cellular and Molecular Immunology, 2014.

[125] J.-S. Thomann, B. Heurtault, S. Weidner et al., "Antitumor activity of liposomal ErbB2/HER2 epitope peptide-based vaccine constructs incorporating TLR agonists and mannose receptor targeting," Biomaterials, vol. 32, no. 20, pp. 4574-4583, 2011.

[126] A. C. Armstrong and D. E. Gilham, "Targeting breast cancer vaccines to dendritic cells: improved immunological responses with less protein?" Breast Cancer Research, vol. 14, article 106, 2012.

[127] M. Tenbusch, G. Nchinda, M. S. G. Bonsmann, V. Temchura, and K. Überla, "Targeting the antigen encoded by adenoviral vectors to the DEC205 receptor modulates the cellular and humoral immune response," International Immunology, vol. 25, no. 4, pp. 247-258, 2013.

[128] I. Caminschi, E. Maraskovsky, and W. R. Heath, "Targeting dendritic cells in vivo for cancer therapy," Frontiers in Immunology, vol. 3, article 13, 2012.

[129] S. Basta and A. Alatery, "The cross-priming pathway: a portrait of an intricate immune system," Scandinavian Journal of Immunology, vol. 65, no. 4, pp. 311-319, 2007.

[130] P. J. Tacken, I. S. Zeelenberg, L. J. Cruz et al., "Targeted delivery of TLR ligands to human and mouse dendritic cells strongly enhances adjuvanticity," Blood, vol. 118, no. 26, pp. 6836-6844, 2011.

[131] L. C. Bonifaz, D. P. Bonnyay, A. Charalambous et al., "In vivo targeting of antigens to maturing dendritic cells via the DEC205 receptor improves T cell vaccination," Journal of Experimental Medicine, vol. 199, no. 6, pp. 815-824, 2004.

[132] J. Idoyaga, A. Lubkin, C. Fiorese et al., "Comparable T helper 1 (Th1) and CD8 T-cell immunity by targeting HIV gag p24 to CD8 dendritic cells within antibodies to Langerin, DEC205, and Clec9A," Proceedings of the National Academy of Sciences of the United States of America, vol. 108, no. 6, pp. 2384-2389, 2011.

[133] J. Tel, S. P. Sittig, R. A. M. Blom et al., "Targeting uptake receptors on human plasmacytoid dendritic cells triggers antigen cross-presentation and robust type I IFN secretion," The Journal of Immunology, vol. 191, no. 10, pp. 5005-5012, 2013.

[134] K. J. Radford, K. M. Tullett, and M. H. Lahoud, "Dendritic cells and cancer immunotherapy," Current Opinion in Immunology, vol. 27, no. 1, pp. 26-32, 2014.

[135] C. P. Chappell, N. V. Giltiay, C. Dresch, and E. A. Clark, "Controlling immune responses by targeting antigens to dendritic cell subsets and B cells," International Immunology, vol. 26, no. 1, pp. 3-11, 2014.

[136] R. Maldonado-López, T. De Smedt, P. Michel et al., "CD8 $\alpha^{+}$and $\mathrm{CD} 8 \alpha^{-}$subclasses of dendritic cells direct the development of 
distinct T helper cells in vivo," Journal of Experimental Medicine, vol. 189, no. 3, pp. 587-592, 1999.

[137] C.-C. Chu, N. Ali, P. Karagiannis et al., "Resident CD141 $(\mathrm{BDCA} 3)^{+}$dendritic cells in human skin produce IL-10 and induce regulatory $\mathrm{T}$ cells that suppress skin inflammation," Journal of Experimental Medicine, vol. 209, no. 5, pp. 935-945, 2012.

[138] D. Sancho, D. Mourão-Sá, O. P. Joffre et al., “Tumor therapy in mice via antigen targeting to a novel, DC-restricted C-type lectin," Journal of Clinical Investigation, vol. 118, no. 6, pp. 20982110, 2008.

[139] O. P. Joffre, D. Sancho, S. Zelenay, A. M. Keller, and C. Reis e Sousa, "Efficient and versatile manipulation of the peripheral $\mathrm{CD}^{+}$T-cell compartment by antigen targeting to DNGR1/CLEC9A," European Journal of Immunology, vol. 40, no. 5, pp. 1255-1265, 2010.

[140] V. Apostolopoulos, G. A. Pietersz, A. Tsibanis et al., "Dendritic cell immunotherapy: clinical outcomes," Clinical \& Translational Immunology, vol. 3, no. 7, article e21, 2014.

[141] K. Kobiyama, T. Aoshi, H. Narita et al., "Nonagonistic Dectin-1 ligand transforms CpG into a multitask nanoparticulate TLR9 agonist," Proceedings of the National Academy of Sciences of the United States of America, vol. 111, no. 8, pp. 3086-3091, 2014.

[142] L. Cohn and L. Delamarre, "Dendritic cell-targeted vaccines," Frontiers in Immunology, vol. 5, article 255, 2014.

[143] K. Kastenmüller, U. Wille-Reece, R. W. B. Lindsay et al., "Protective $\mathrm{T}$ cell immunity in mice following protein-TLR7/8 agonistconjugate immunization requires aggregation, type I IFN, and multiple DC subsets," The Journal of Clinical Investigation, vol. 121, no. 5, pp. 1782-1796, 2011.

[144] K. Sehgal, R. Ragheb, T. M. Fahmy, M. V. Dhodapkar, and K. M. Dhodapkar, "Nanoparticle-mediated combinatorial targeting of multiple human dendritic cell (DC) subsets leads to enhanced T cell activation via IL-15-dependent DC crosstalk," Journal of Immunology, vol. 193, no. 5, pp. 2297-2305, 2014.

[145] F. Wimmers, G. Schreibelt, A. E. Sköld, C. G. Figdor, and I. J. M. De Vries, "Paradigm shift in dendritic cell-based immunotherapy: from in vitro generated monocyte-derived DCs to naturally circulating DC subsets," Frontiers in Immunology, vol. 5, article $165,2014$.

[146] G. Grødeland, S. Mjaaland, G. Tunheim, A. B. Fredriksen, and B. Bogen, "The specificity of targeted vaccines for APC surface molecules influences the immune response phenotype," PLoS ONE, vol. 8, no. 11, Article ID e80008, 2013.

[147] E. Macho-Fernandez, L. J. Cruz, R. Ghinnagow et al., “Targeted delivery of $\alpha$-galactosylceramide to $\mathrm{CD} 8 \alpha^{+}$dendritic cells optimizes type I NKT cell-based antitumor responses," Journal of Immunology, vol. 193, no. 2, pp. 961-969, 2014.

[148] B. Wang, "Targeting dendritic cells in situ for breast cancer immunotherapy," OncoImmunology, vol. 1, no. 8, pp. 1398-1400, 2012.

[149] B. Wang, N. Zaidi, L.-Z. He et al., "Targeting of the non-mutated tumor antigen HER2/neu to mature dendritic cells induces an integrated immune response that protects against breast cancer in mice," Breast Cancer Research, vol. 14, no. 2, article R39, 2012.

[150] B. Wang, J. M. Y. Kuroiwa, L.-Z. He, A. Charalambous, T. Keler, and R. M. Steinman, "The human cancer antigen mesothelin is more efficiently presented to the mouse immune system when targeted to the DEC-205/CD205 receptor on dendritic cells," Annals of the New York Academy of Sciences, vol. 1174, pp. 6-17, 2009.
[151] R. Sartorius, C. Bettua, L. D’Apice et al., "Vaccination with filamentous bacteriophages targeting DEC-205 induces DC maturation and potent anti-tumor T-cell responses in the absence of adjuvants," European Journal of Immunology, vol. 41, no. 9, pp. 2573-2584, 2011.

[152] K. Mahnke, Y. Qian, S. Fondel, J. Brueck, C. Becker, and A. H. Enk, "Targeting of antigens to activated dendritic cells in vivo cures metastatic melanoma in mice," Cancer Research, vol. 65, no. 15, pp. 7007-7012, 2005.

[153] J. Cao, Y. Jin, W. Li et al., "DNA vaccines targeting the encoded antigens to dendritic cells induce potent antitumor immunity in mice," BMC Immunology, vol. 14, article 39, 2013.

[154] M. V. Dhodapkar, M. Sznol, B. Zhao et al., "Induction of antigen-specific immunity with a vaccine targeting NY-ESO-1 to the dendritic cell receptor DEC-205," Science Translational Medicine, vol. 6, no. 232, Article ID 232ra51, 2014.

[155] J. M. Silva, E. Zupancic, G. Vandermeulen et al., "In vivo delivery of peptides and Toll-like receptor ligands by mannosefunctionalized polymeric nanoparticles induces prophylactic and therapeutic anti-tumor immune responses in a melanoma model," Journal of Controlled Release, vol. 198, pp. 91-103, 2015.

[156] L.-Z. He, A. Crocker, J. Lee et al., "Antigenic targeting of the human mannose receptor induces tumor immunity," Journal of Immunology, vol. 178, no. 10, pp. 6259-6267, 2007.

[157] V. Apostolopoulos, G. A. Pietersz, and I. F. C. McKenzie, "Cellmediated immune responses to MUC1 fusion protein coupled to mannan," Vaccine, vol. 14, no. 9, pp. 930-938, 1996.

[158] K.-C. Sheng, M. Kalkanidis, D. S. Pouniotis et al., "Delivery of antigen using a novel mannosylated dendrimer potentiates immunogenicity in vitro and in vivo," European Journal of Immunology, vol. 38, no. 2, pp. 424-436, 2008.

[159] Z. Cui, S.-J. Han, and L. Huang, "Coating of mannan on LPD particles containing HPV E7 peptide significantly enhances immunity against HPV-positive tumor," Pharmaceutical Research, vol. 21, no. 6, pp. 1018-1025, 2004.

[160] F. Perche, T. Benvegnu, M. Berchel et al., "Enhancement of dendritic cells transfection in vivo and of vaccination against B16F10 melanoma with mannosylated histidylated lipopolyplexes loaded with tumor antigen messenger RNA," Nanomedicine: Nanotechnology, Biology, and Medicine, vol. 7, no. 4, pp. 445-453, 2011.

[161] M. Mockey, E. Bourseau, V. Chandrashekhar et al., "mRNAbased cancer vaccine: prevention of B16 melanoma progression and metastasis by systemic injection of MART1 mRNA histidylated lipopolyplexes," Cancer Gene Therapy, vol. 14, no. 9, pp. 802-814, 2007.

[162] H. Shiku, L. Wang, Y. Ikuta et al., "Development of a cancer vaccine: peptides, proteins, and DNA," Cancer Chemotherapy and Pharmacology, vol. 46, supplement, pp. S77-S82, 2000.

[163] P. M. Moyle, C. Olive, M.-F. Ho et al., "Toward the development of prophylactic and therapeutic human papillomavirus type-16 lipopeptide vaccines," Journal of Medicinal Chemistry, vol. 50, no. 19, pp. 4721-4727, 2007.

[164] M. A. Morse, R. Chapman, J. Powderly et al., "Phase I study utilizing a novel antigen-presenting cell-targeted vaccine with toll-like receptor stimulation to induce immunity to selfantigens in cancer patients," Clinical Cancer Research, vol. 17, no. 14, pp. 4844-4853, 2011.

[165] B. Hu, H. Yang, B. Dai, A. Tai, and P. Wang, "Nonintegrating lentiviral vectors can effectively deliver ovalbumin antigen for induction of antitumor immunity," Human Gene Therapy, vol. 20, no. 12, pp. 1652-1664, 2009. 
[166] A. Kretz-Rommel, F. Qin, N. Dakappagari et al., "In vivo targeting of antigens to human dendritic cells through DCSIGN elicits stimulatory immune responses and inhibits tumor growth in grafted mouse models," Journal of Immunotherapy, vol. 30, no. 7, pp. 715-726, 2007.

[167] J. M. Odegard, B. Kelley-Clarke, S. U. Tareen et al., "Virological and preclinical characterization of a dendritic cell targeting, integration-deficient lentiviral vector for cancer immunotherapy," Journal of Immunotherapy, vol. 38, no. 2, pp. 41-53, 2015.

[168] S. U. Tareen, B. Kelley-Clarke, C. J. Nicolai et al., "Design of a novel integration-deficient lentivector technology that incorporates genetic and posttranslational elements to target human dendritic cells," Molecular Therapy, vol. 22, no. 3, pp. 575-587, 2014.

[169] Y. Delneste, G. Magistrelli, J.-F. Gauchat et al., "Involvement of LOX-1 in dendritic cell-mediated antigen cross-presentation," Immunity, vol. 17, no. 3, pp. 353-362, 2002.

[170] G. Picco, R. Beatson, J. Taylor-Papadimitriou, and J. M. Burchell, "Targeting DNGR-1 (CLEC9A) with antibody/MUC1 peptide conjugates as a vaccine for carcinomas," European Journal of Immunology, vol. 44, no. 7, pp. 1947-1955, 2014.

[171] K. Neubert, C. H. K. Lehmann, L. Heger et al., "Antigen delivery

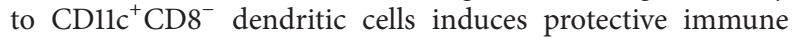
responses against experimental melanoma in mice in vivo," Journal of Immunology, vol. 192, no. 12, pp. 5830-5838, 2014.

[172] T. Akazawa, T. Ohashi, H. Nakajima et al., "Development of a dendritic cell-targeting lipopeptide as an immunoadjuvant that inhibits tumor growth without inducing local inflammation," International Journal of Cancer, vol. 135, no. 12, pp. 2847-2856, 2014.

[173] A. Faham and J. G. Altin, "Ag-bearing liposomes engrafted with peptides that interact with CD11c/CD18 induce potent Ag-specific and antitumor immunity," International Journal of Cancer, vol. 129, no. 6, pp. 1391-1403, 2011.

[174] X. Préville, D. Ladant, B. Timmerman, and C. Leclerc, "Eradication of established tumors by vaccination with recombinant Bordetella pertussis adenylate cyclase carrying the human papillomavirus 16 E7 oncoprotein," Cancer Research, vol. 65, no. 2, pp. 641-649, 2005.

[175] S. N. Furlan, R. Mandraju, T. Brewer et al., "Enhancement of anti-tumor CD8 immunity by IgG1-mediated targeting of Fc receptors," $m A$ Abs, vol. 6, no. 1, pp. 108-118, 2014.

[176] I. G. Zizzari, F. Veglia, F. Taurino et al., "HER2-based recombinant immunogen to target DCs through Fc $\gamma$ Rs for cancer immunotherapy," Journal of Molecular Medicine, vol. 89, no. 12, pp. 1231-1240, 2011.

[177] P. Daftarian, A. E. Kaifer, W. Li et al., "Peptide-conjugated PAMAM dendrimer as a universal DNA vaccine platform to target antigen-presenting cells," Cancer Research, vol. 71, no. 24, pp. 7452-7462, 2011.

[178] A. Ageichik, C. J. Buchholz, and M. K. Collins, "Lentiviral vectors targeted to MHC II are effective in immunization," Human Gene Therapy, vol. 22, no. 10, pp. 1249-1254, 2011.

[179] F. Gennari, L. Lopes, E. Verhoeyen, W. Marasco, and M. K. Collins, "Single-chain antibodies that target lentiviral vectors to MHC class II on antigen-presenting cells," Human Gene Therapy, vol. 20, no. 6, pp. 554-562, 2009.

[180] A. B. Fredriksen, I. Sandlie, and B. Bogen, "Targeted DNA vaccines for enhanced induction of idiotype-specific $\mathrm{B}$ and $\mathrm{T}$ cells," Frontiers in Oncology, vol. 2, article 154, 2012.

[181] M. Frøyland, P. A. Ruffini, K. M. Thompson, T. Gedde-Dahl, A. B. Fredriksen, and B. Bogen, "Targeted idiotype-fusion DNA vaccines for human multiple myeloma: preclinical testing," European Journal of Haematology, vol. 86, no. 5, pp. 385-395, 2011.

[182] J. Loschko, A. Schlitzer, D. Dudziak et al., "Antigen delivery to plasmacytoid dendritic cells via BST2 induces protective T cellmediated immunity," The Journal of Immunology, vol. 186, no. 12, pp. 6718-6725, 2011.

[183] D. Muraoka, N. Harada, T. Hayashi et al., "Nanogel-based immunologically stealth vaccine targets macrophages in the medulla of lymph node and induces potent antitumor immunity," ACS Nano, vol. 8, no. 9, pp. 9209-9218, 2014.

[184] L. M. Wood and Y. Paterson, "Attenuated Listeria monocytogenes: a powerful and versatile vector for the future of tumor immunotherapy," Frontiers in Cellular and Infection Microbiology, vol. 4, article 51, 2014.

[185] C. Perez-Shibayama, C. Gil-Cruz, M. Nussbacher et al., "Dendritic cell-specific delivery of flt3l by coronavirus vectors secures induction of therapeutic antitumor immunity, PLoS ONE, vol. 8, no. 11, Article ID e81442, 2013.

[186] L. Cervantes-Barragan, R. Züst, R. Maier et al., "Dendritic cell-specific antigen delivery by coronavirus vaccine vectors induces long-lasting protective antiviral and antitumor immunity," mBio, vol. 1, no. 4, 2010.

[187] P. Duewell, U. Kisser, K. Heckelsmiller et al., "ISCOMATRIX adjuvant combines immune activation with antigen delivery to dendritic cells in vivo leading to effective cross-priming of $\mathrm{CD}^{+}$T cells," Journal of Immunology, vol. 187, no. 1, pp. 55-63, 2011.

[188] R. A. Rosalia, L. J. Cruz, S. van Duikeren et al., "CD40-targeted dendritic cell delivery of PLGA-nanoparticle vaccines induce potent anti-tumor responses," Biomaterials, vol. 40, pp. 88-97, 2015.

[189] B. J. Williams, S. Bhatia, L. K. Adams et al., "Dendritic cell based PSMA immunotherapy for prostate cancer using a CD40targeted adenovirus vector," PLoS ONE, vol. 7, no. 10, Article ID e46981, 2012.

[190] B. N. Hangalapura, D. Oosterhoff, J. de Groot et al., "Potent antitumor immunity generated by a CD40-targeted adenoviral vaccine," Cancer Research, vol. 71, no. 17, pp. 5827-5837, 2011.

[191] B. N. Hangalapura, D. Oosterhoff, S. Aggarwal et al., "Selective transduction of dendritic cells in human lymph nodes and superior induction of high-avidity melanoma-reactive cytotoxic $\mathrm{T}$ cells by a CD40-targeted adenovirus," Journal of Immunother$a p y$, vol. 33, no. 7, pp. 706-715, 2010.

[192] U. E. Burkhardt, A. Sloots, V. Jakobi et al., "IL-15 augments antitumoral activity of an ErbB2/HER2 cancer vaccine targeted to professional antigen-presenting cells," Cancer Immunology, Immunotherapy, vol. 61, no. 9, pp. 1473-1484, 2012.

[193] H. Hemmi, N. Zaidi, B. Wang et al., "Treml4, an Ig superfamily member, mediates presentation of several antigens to $\mathrm{T}$ cells in vivo, including protective immunity to HER2 protein," The Journal of Immunology, vol. 188, no. 3, pp. 1147-1155, 2012.

[194] H. J. Cho, K. Takabayashi, P.-M. Cheng et al., "Immunostimulatory DNA-based vaccines induce cytotoxic lymphocyte activity by a T-helper cell-independent mechanism," Nature Biotechnology, vol. 18, no. 5, pp. 509-514, 2000.

[195] D. C. Jackson, F. L. Yuk, T. Le et al., "A totally synthetic vaccine of generic structure that targets Toll-like receptor 2 on dendritic cells and promotes antibody or cytotoxic T cell responses," Proceedings of the National Academy of Sciences of the United States of America, vol. 101, no. 43, pp. 15440-15445, 2004. 
[196] A. K. Panda, "Induction of anti-tumor immunity and T-cell responses using nanodelivery systems engrafting TLR-5 ligand," Expert Review of Vaccines, vol. 10, no. 2, pp. 155-157, 2011.

[197] C. Mansilla, P. Berraondo, M. Durantez et al., "Eradication of large tumors expressing human papillomavirus E7 protein by therapeutic vaccination with E7 fused to the extra domain a from fibronectin," International Journal of Cancer, vol. 131, no. 3, pp. 641-651, 2012.

[198] F. Aranda, D. Llopiz, N. Díaz-Valdés et al., "Adjuvant combination and antigen targeting as a strategy to induce polyfunctional and high-avidity T-cell responses against poorly immunogenic tumors," Cancer Research, vol. 71, no. 9, pp. 3214-3224, 2011.

[199] A. Biragyn, K. Tani, M. C. Grimm, S. Weeks, and L. W. Kwak, "Genetic fusion of chemokines to a self tumor antigen induces protective, T-cell dependent antitumor immunity," Nature Biotechnology, vol. 17, no. 3, pp. 253-258, 1999.

[200] E. Hartung, M. Becker, A. Bachem et al., "Induction of potent CD8 T cell cytotoxicity by specific targeting of antigen to crosspresenting dendritic cells in vivo via murine or human XCR1," The Journal of Immunology, vol. 194, no. 3, pp. 1069-1079, 2015. 


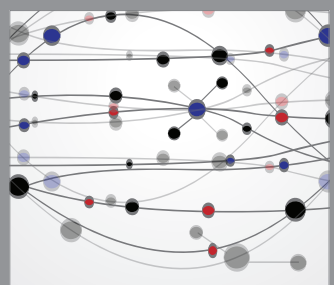

The Scientific World Journal
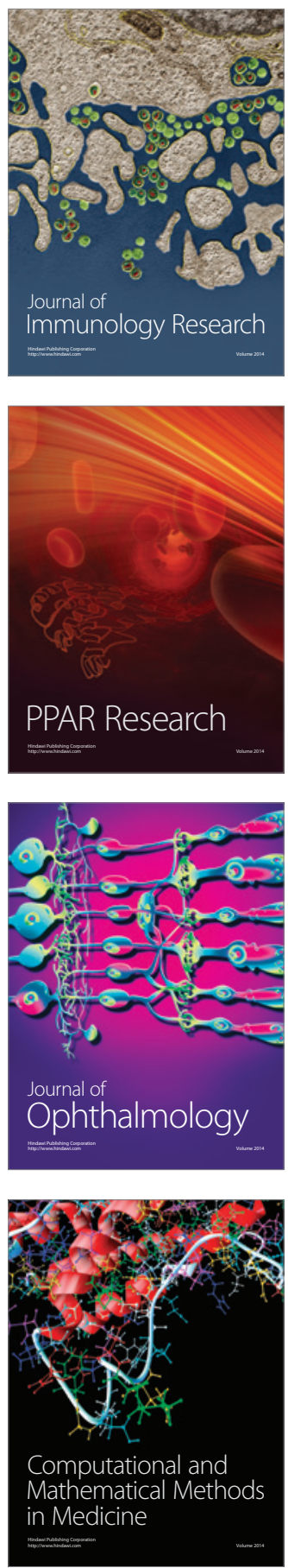

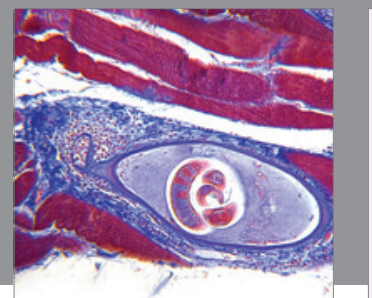

Gastroenterology

Research and Practice
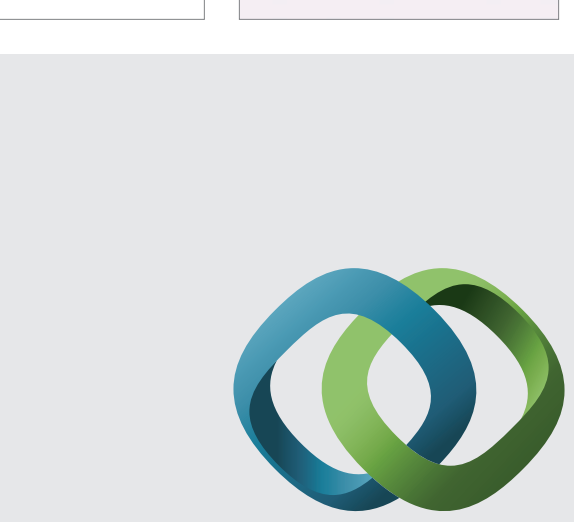

\section{Hindawi}

Submit your manuscripts at

http://www.hindawi.com
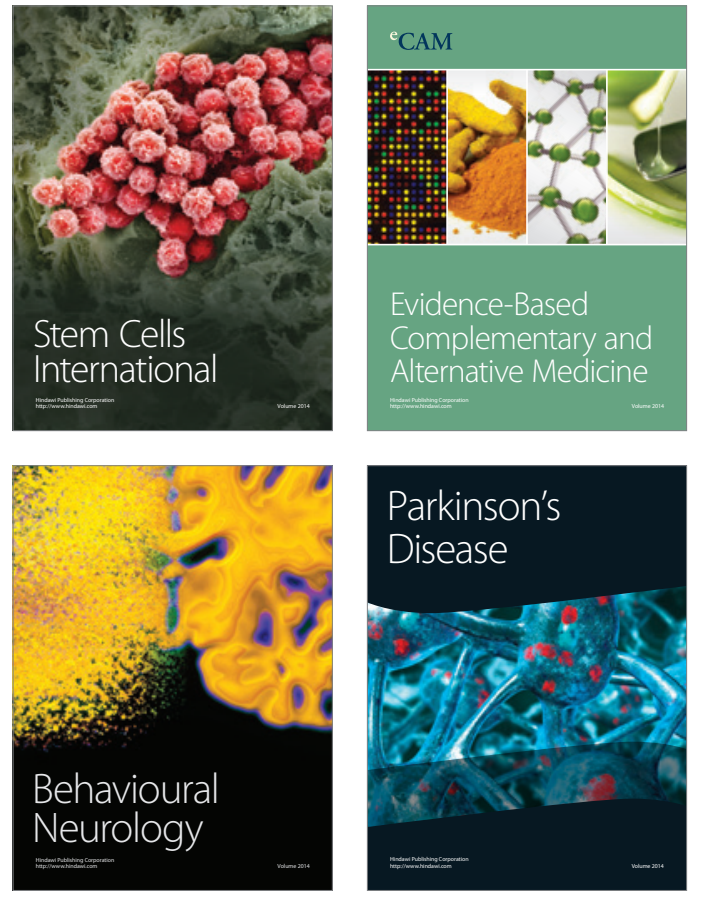
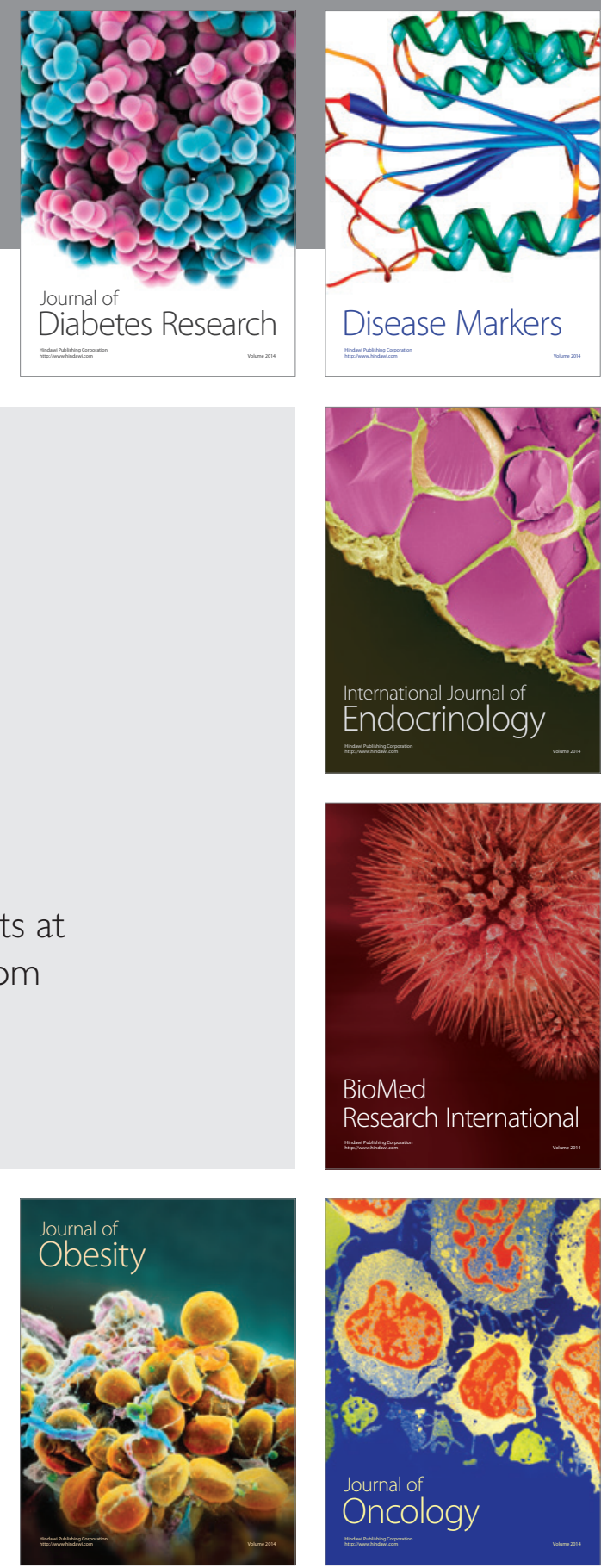

Disease Markers
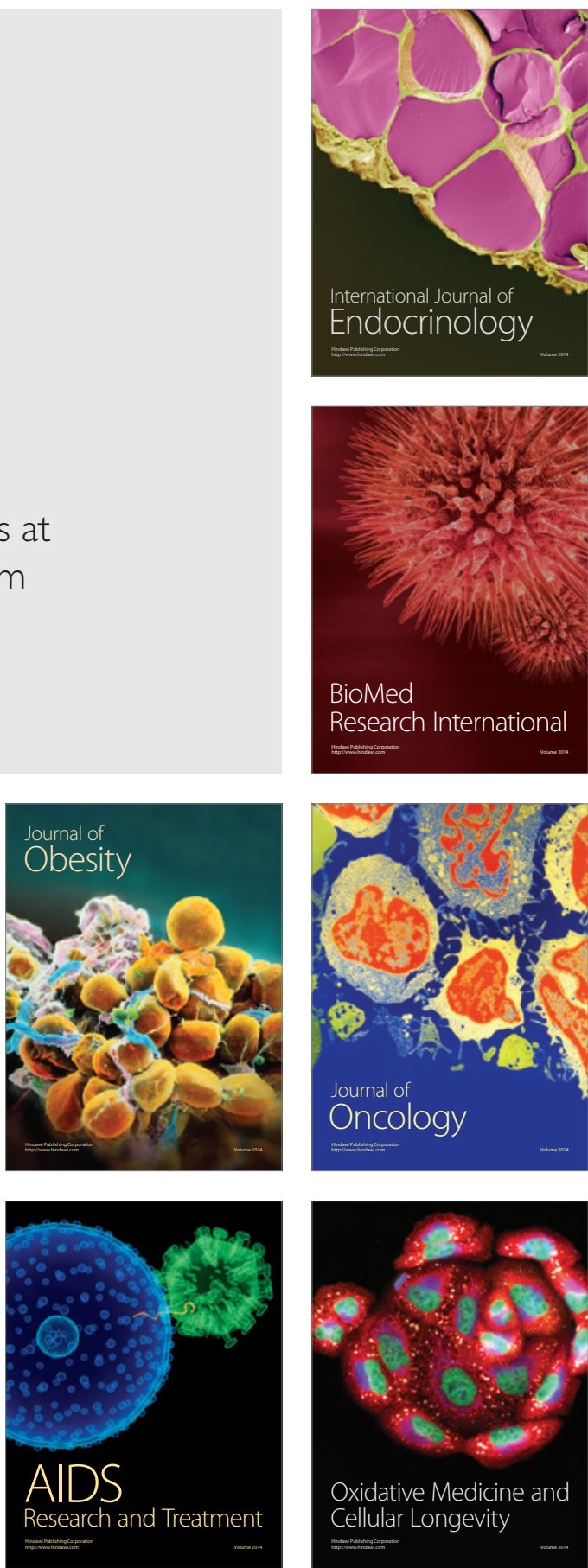